University of Nebraska - Lincoln

DigitalCommons@University of Nebraska - Lincoln

Publications from USDA-ARS / UNL Faculty

U.S. Department of Agriculture: Agricultural

Research Service, Lincoln, Nebraska

$11-6-2018$

\title{
Herbicide Metabolism: Crop Selectivity, Bioactivation, Weed Resistance, and Regulation
}

Vijay K. Nandula

Crop Production Systems Research Unit, USDA-ARS, vijay.nandula@ars.usda.gov

Dean E. Riechers

University of Illinois, riechers@illinois.edu

Yurdagul Ferhatoglu

University of Kentucky

Michael Barrett

University of Kentucky

Stephen O. Duke

Natural Products Utilization Research Unit, USDA-ARS

See next page for additional authors

Follow this and additional works at: https://digitalcommons.unl.edu/usdaarsfacpub

Nandula, Vijay K.; Riechers, Dean E.; Ferhatoglu, Yurdagul; Barrett, Michael; Duke, Stephen O.; Dayan, Franck E.; Goldberg-Cavalleri, Alina; Tétard-Jones, Catherine; Wortley, David J.; Onkokesung, Nawaporn; Brazier-Hicks, Melissa; Edwards, Robert; Gaines, Todd; Iwakami, Satoshi; Jugulam, Mithila; and Ma, Rong, "Herbicide Metabolism: Crop Selectivity, Bioactivation, Weed Resistance, and Regulation" (2018).

Publications from USDA-ARS / UNL Faculty. 2165.

https://digitalcommons.unl.edu/usdaarsfacpub/2165

This Article is brought to you for free and open access by the U.S. Department of Agriculture: Agricultural Research Service, Lincoln, Nebraska at DigitalCommons@University of Nebraska - Lincoln. It has been accepted for inclusion in Publications from USDA-ARS / UNL Faculty by an authorized administrator of DigitalCommons@University of Nebraska - Lincoln. 


\section{Authors}

Vijay K. Nandula, Dean E. Riechers, Yurdagul Ferhatoglu, Michael Barrett, Stephen O. Duke, Franck E. Dayan, Alina Goldberg-Cavalleri, Catherine Tétard-Jones, David J. Wortley, Nawaporn Onkokesung, Melissa Brazier-Hicks, Robert Edwards, Todd Gaines, Satoshi Iwakami, Mithila Jugulam, and Rong Ma 


\section{Symposium}

Cite this article: Nandula VK, Riechers DE, Ferhatoglu Y, Barrett M, Duke SO, Dayan FE, DJ, Onkokesung N, Brazier-Hicks M, Edwards R, Gaines T, Iwakami S, Jugulam M, Ma R (2019) Herbicide metabolism: crop selectivity, bioactivation, weed resistance, and regulation. Weed Sci 67:149-175. doi: $10.1017 /$ wsc. 2018.88

Received: 2 July 2018

Revised: 5 November 2018

Accepted: 6 November 2018

\section{Associate Editor:}

Patrick J. Tranel, University of Illinois

\section{Key words:}

Crop tolerance; cytochrome P450; glutathione; glutathione S-transferase; herbicide safener; natural phytotoxin; oxylipin

\section{Author for correspondence:} Station Road, Stoneville, MS 38776.

(Email: vijay.nandula@ars.usda.gov) Goldberg-Cavalleri A, Tétard-Jones C, Wortley

Vijay Nandula, USDA-ARS, 141 Experiment

\section{Herbicide Metabolism: Crop Selectivity, Bioactivation, Weed Resistance, and Regulation}

\author{
Vijay K. Nandula ${ }^{1}$, Dean E. Riechers ${ }^{2}$, Yurdagul Ferhatoglu ${ }^{3}$, Michael Barrett ${ }^{3}$, \\ Stephen O. Duke ${ }^{4}$, Franck E. Dayan ${ }^{5}$, Alina Goldberg-Cavalleri ${ }^{6}$, Catherine \\ Tétard-Jones ${ }^{6}$, David J. Wortley ${ }^{7}$, Nawaporn Onkokesung ${ }^{6}$, Melissa Brazier- \\ Hicks $^{6}$, Robert Edwards ${ }^{6}$, Todd Gaines ${ }^{5}$, Satoshi Iwakami ${ }^{8}$, Mithila Jugulam ${ }^{9}$ \\ and Rong $\mathrm{Ma}^{10}$
}

\begin{abstract}
${ }^{1}$ Research Plant Physiologist, Crop Production Systems Research Unit, USDA-ARS, Stoneville, MS, USA, ${ }^{2}$ Professor, Department of Crop Sciences, University of Illinois, Urbana, IL, USA, ${ }^{3}$ Former Graduate Student and Professor, Department of Plant and Soil Sciences, University of Kentucky, Lexington, KY, USA, ${ }^{4}$ Research Leader, Natural Products Utilization Research Unit, USDA-ARS, University, MS, USA, ${ }^{5}$ Professor and Assistant Professor, Department of Bioagricultural Sciences and Pest Management, Colorado State University, Fort Collins, CO, USA, ${ }^{6}$ Research Associate, Research Fellow, Research Associate, Senior Research Associate, and Professor, School of Natural and Environmental Sciences, Newcastle University, Newcastle upon Tyne, UK, ${ }^{7}$ Boult Wade Tennant, London, UK, ${ }^{8}$ Assistant Professor, Kyoto University, Kyoto, Japan, ${ }^{9}$ Associate Professor, Department of Agronomy, Kansas State University, Manhattan, KS, USA and ${ }^{10}$ Assistant Professor, Department of Plant Sciences, University of Idaho, Moscow, ID, USA
\end{abstract}

\section{Abstract}

Several grass and broadleaf weed species around the world have evolved multiple-herbicide resistance at alarmingly increasing rates. Research on the biochemical and molecular resistance mechanisms of multiple-resistant weed populations indicate a prevalence of herbicide metabolism catalyzed by enzyme systems such as cytochrome P450 monooxygenases and glutathione $S$-transferases and, to a lesser extent, by glucosyl transferases. A symposium was conducted to gain an understanding of the current state of research on metabolic resistance mechanisms in weed species that pose major management problems around the world. These topics, as well as future directions of investigations that were identified in the symposium, are summarized herein. In addition, the latest information on selected topics such as the role of safeners in inducing crop tolerance to herbicides, selectivity to clomazone, glyphosate metabolism in crops and weeds, and bioactivation of natural molecules is reviewed.
This document is a U.S. government work and is not subject to copyright in the United States.

(c) Weed Science Society of America, 2019.

\section{Introduction}

A common mode of tolerance to herbicides in agronomic crops is by metabolism brought about by enzyme systems such as cytochrome P450s (CYPs), glutathione $S$-transferases (GSTs), and glucosyl transferases (GTs). These enzymes, as well as cofactors such as reduced glutathione (GSH), are activated by certain chemicals called safeners (Riechers et al. 2010). Safeners are applied in combination with herbicides to provide tolerance in grass crops such as wheat (Triticum aestivum L.), rice (Oryza sativa L.), corn (Zea mays L.), and grain sorghum [(Sorghum bicolor (L.) Moench.] against certain thiocarbamate, chloroacetamide, sulfonylurea (SU), and aryoxyphenoxypropionate (AOPP) herbicides applied PRE or POST. Metabolism of herbicides usually occurs in three phases: a conversion of the herbicide molecule into a more hydrophilic metabolite (Phase 1); followed by conjugation to biomolecules such as glutathione/sugar (Phase 2); and further conjugation/breakup/oxidation reactions with subsequent transport to vacuoles or cell walls, where additional breakdown or sequestration occurs (Phase 3 ).

The next and most important phase after the confirmation of herbicide resistance in a weed population is the deciphering of the underlying resistance mechanism(s), which can greatly determine the effectiveness of resistance management strategies. One of the common mechanisms of resistance is metabolic deactivation, whereby the herbicide active ingredient is transformed to nonphytotoxic metabolites (Yu and Powles 2014).

An immediate and urgent challenge for weed scientists is to understand and characterize the basis of metabolic resistance to sustain the limited herbicide portfolio and develop integrated weed management strategies. Metabolic resistance research in weeds has mostly been 
limited to grass species such as rigid ryegrass (Lolium rigidum Gaudin), blackgrass (Alopecurus myusuroides Huds.), and Echinochloa spp. However, dicot species such as waterhemp [Amaranthus tuberculatus (Moq.) J. D. Sauer] and Palmer amaranth (Amaranthus palmeri S. Watson) have evolved resistance to herbicides with different mechanisms of action by enhanced metabolic degradation. Thus, both grass and dicot weed species that develop metabolic herbicide resistance can pose a severe management challenge.

The main objective of this symposium was to gain an understanding of current research on metabolic resistance in weeds by revisiting the history of related research, including crop tolerance; reporting recent advances; and identifying future research opportunities. This report is not an exhaustive all-encompassing review of herbicide metabolism in crops and weeds; it is a compilation of papers presented at a symposium during the 2018 Weed Science Society of America annual meeting.

\section{Complex Signaling, Defense, and Detoxification Pathways in Safener-treated Grain Sorghum Shoots}

Induction of herbicide-detoxification enzymes catalyzing Phase I to III metabolic reactions by safeners is well documented (Cummins et al. 2011; Theodoulou et al. 2003; Zhang et al. 2007) and has been reviewed extensively in recent years (Kraehmer et al. 2014; Riechers and Green 2017; Riechers et al. 2010). However, identification of signaling genes and pathways leading to safenerinduced herbicide metabolism has remained mostly elusive. Recent research findings have indicated oxidized lipids, or oxylipins, play an important role in plant defense responses to abiotic and biotic stresses (Hou et al. 2016; Mueller and Berger 2009) and may also play a key role in safener-mediating signaling (BrazierHicks et al. 2018; Matsumoto et al. 2015; Riechers et al. 2010; Skipsey et al. 2011). In addition to oxylipins, plant hormones such as salicylic acid and jasmonic acid (JA) regulate many plant responses to pathogen attack or herbivore injury (Gao et al. 2015; Koo 2018; Larrieu and Vernoux 2016) and may also function in safener-regulated responses (Behringer et al. 2011).

Although a precise signaling cascade has yet to be established for safener-regulated induction of herbicide detoxification in cereal crops, several new hypotheses and research areas have recently emerged involving oxylipins and other signaling molecules that will be the subject of future studies. In addition to unraveling the complex signaling pathways that lead to the induction of enzymes involved in herbicide detoxification, recent research has also shown that tissue- and cell-specific expression of these enzymes may also play an important role in safener mechanisms of action in cereal crops (reviewed by Riechers et al. 2010) and may potentially explain why dicot plants do not respond to safener treatments with increased crop tolerance despite increased gene and protein expression (DeRidder and Goldsbrough 2006). These two topics will be the focus of the following sections.

\section{Oxylipin Involvement in Safener-mediated Signaling}

A key finding from research in the mid-2000s was that several classes of oxylipins (Mosblech et al. 2009; Mueller 2004) are detected in plants following exposure to stresses, and subsequent work demonstrated that oxylipins induce the expression of plant defense and detoxification genes that mimic safener-induced genes and proteins (Loeffler et al. 2005; Mueller et al. 2008;
Riechers et al. 2010; Zhang et al. 2007). Two major categories of oxylipins have been detected in plants (Cuyamendous et al. 2015; Durand et al. 2011; Mosblech et al. 2009; Mueller and Berger 2009): (1) phytoprostanes and phytofurans, which are categorized based on their nonenzymatic formation via interaction of reactive oxygen species with $\alpha$-linolenic acid (ALA); and (2) enzymatic conversion of ALA to 12-oxo-phytodienoic acid (OPDA) and subsequent $ß$-oxidation to yield JA (Figure 1). Interestingly, the enzyme catalyzing conversion of OPDA to 3-oxo-2-(2-pentenyl)cyclopentaneoctanoic acid (OPC-8:0, the precursor of JA), OPDA reductase (OPR), has been frequently identified in transcript- or protein-profiling studies of plant responses to stress (Okazaki and Saito 2014; Taki et al. 2005; Yan et al. 2012), including safenertreated plants and tissues (Riechers et al. 2010; Rishi et al. 2004; Zhang et al. 2007).

Recent research has investigated possible links between oxylipin-mediated defense signaling and safener mechanism of action. The tau-class AtGSTU19 enzyme catalyzed the conjugation of GSH to OPDA (Dixon and Edwards 2010), leading to a reduction in GSH reactivity. As mentioned earlier, OPR enzymes reduce the double bond in the cyclopentenone ring of OPDA, resulting in an analogous reduction in reactivity (i.e., electrophilicity) but also leading toward biosynthesis of JA (Mueller and Berger 2009). Root cultures from Arabidopsis mutants defective in

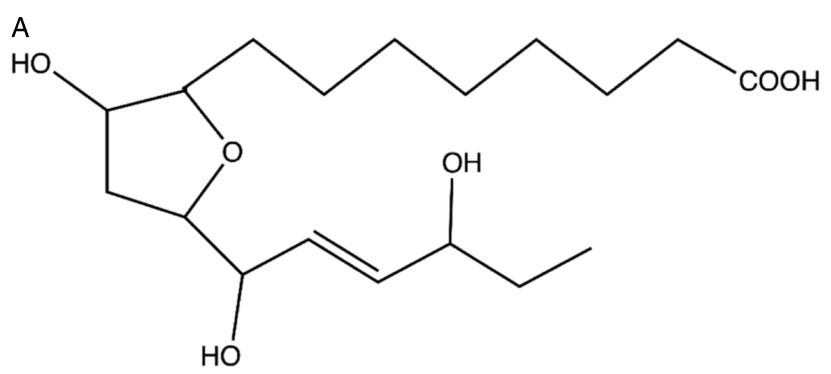

B

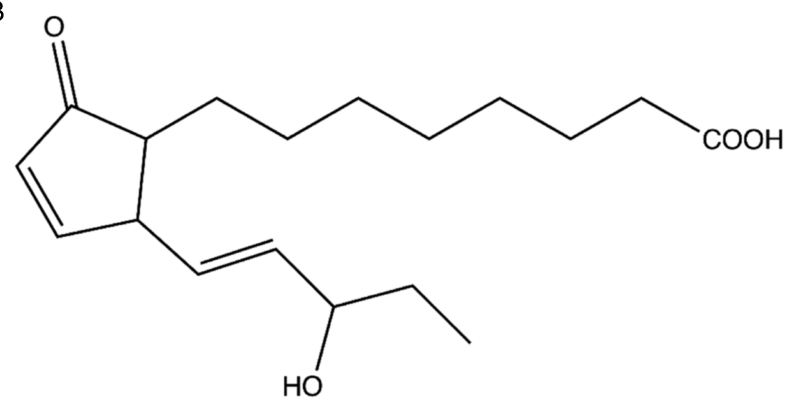

C

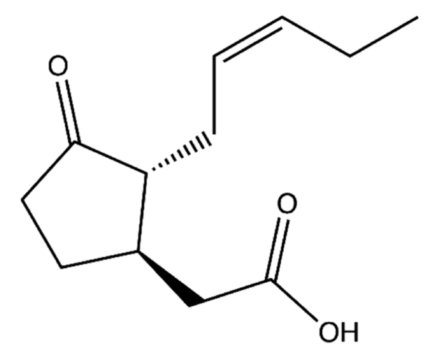

Figure 1. Representative structures of oxidized lipids (oxylipins) formed in plants. Two classes of oxylipins are generated from $\alpha$-linolenic acid as substrate; either nonenzymatically formed ( $A$, generalized phytofuran; or $B$, phytoprostane) via interaction with reactive oxygen species or enzymatically synthesized (C, jasmonic acid). For more details on structures and biosynthetic pathways see Cuyamendous et al. (2015), Durand et al. (2011), and Mosblech et al. (2009). 

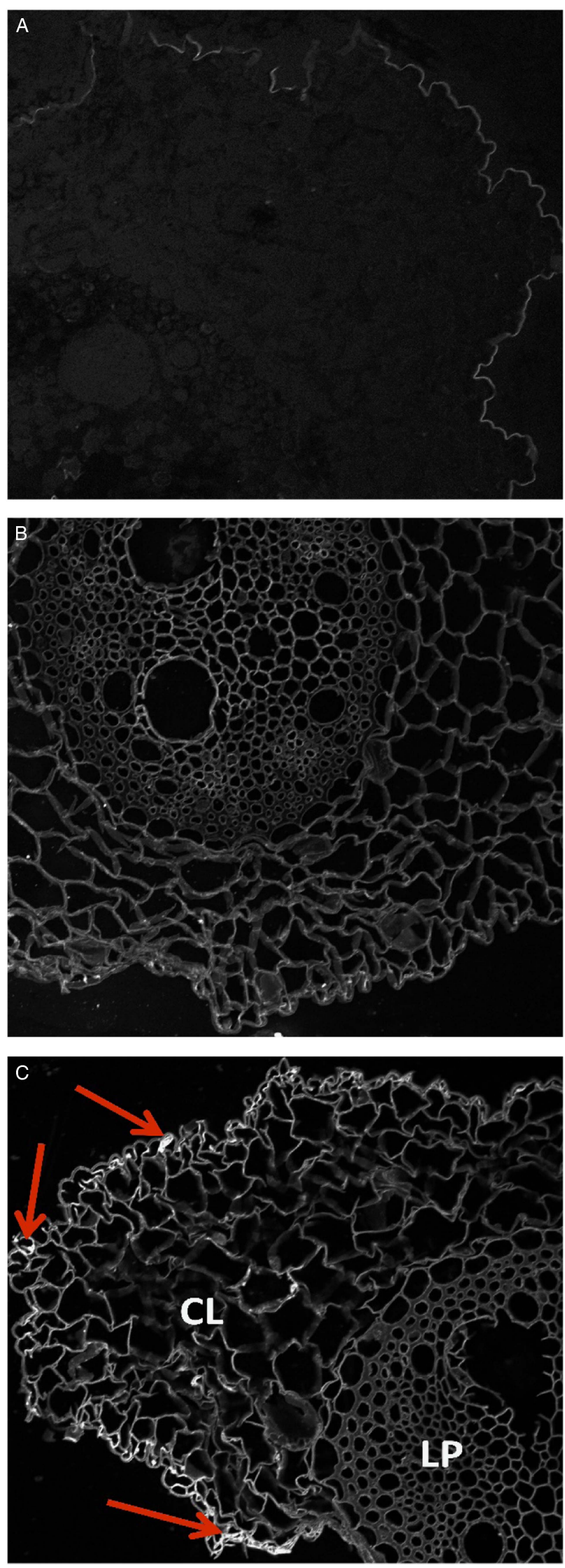

fatty-acid desaturation ( $f a d 3-2 / f a d 7-2 / f a d 8)$, which are impaired in forming the oxylipin precursor ALA, demonstrated a decreased ability to respond to safener treatment when AtGSTU24 expression was measured and compared with expression in wild-type Arabidopsis (Skipsey et al. 2011). Because these fad mutants accumulate linoleic acid (18:2) instead of ALA (18:3), they are unable to synthesize OPDA or phytoprostanes from ALA substrate released via lipase activities (Christeller and Galis 2014). The decreased ability of these mutant lines to respond to safener treatment via induction of GST expression is consistent with a link between safener-regulated responses and endogenous oxylipin signaling.

Based on the literature regarding oxylipin-regulated gene expression (Mueller and Berger 2009) and recent results with fad mutants in Arabidopsis (Skipsey et al. 2011), it was postulated that certain oxylipins may not only rapidly induce genes involved in herbicide detoxification pathways but may also confer safener activity in cereals (Brazier-Hicks et al. 2018; Riechers et al. 2010). To directly test this hypothesis, a series of compounds modeled on oxylipin structures were chemically synthesized and tested for biological activity as herbicide safeners in rice (Brazier-Hicks et al. 2018), in comparison with the commercial rice safener fenclorim. Three of the 21 compounds tested rapidly induced GST expression in Arabidopsis, but only showed minor whole-plant safening activity against pretilachlor herbicide in rice seedlings. In addition to possible species-specific differences in responses to these potential crop-safening compounds (Brazier-Hicks et al. 2018), metabolic pathways and turnover rates of oxylipins (Dueckershoff et al. 2008) may differ significantly from those of commercial safeners in tissues of cereal crop seedlings (Miller et al. 1996; Riechers et al. 2010), therefore requiring further investigation.

\section{Organ-, Tissue-, and Cell-Specific Expression of Safener- induced Detoxification Enzymes}

As described previously, although the precise signaling pathway (s) that regulate gene expression within herbicide detoxification pathways have not been elucidated, previous research demonstrated that tau-class GST proteins and GST enzyme activities involved in herbicide detoxification are highly expressed in the outermost cells of wheat seedling coleoptiles after safener treatment (Riechers et al. 2003). Interestingly, similar results were found in safener-treated sorghum coleoptiles using the same tauclass wheat GST antiserum (Figure 2). Additional research examining stress-responsive gene expression in Arabidopsis cell cultures (Mueller et al. 2008) and protein abundance in leaves (Dueckershoff et al. 2008) showed that oxylipins (such as phytoprostanes or OPDA) trigger detoxification and defense responses in a manner similar to safener treatments. Current experiments were designed to test the hypothesis that safeners

Figure 2. Tissue distribution of glutathione S-transferase (GST) proteins in a cross section of etiolated grain sorghum seedlings, probed with an antiserum raised against the tau-class TtGSTU1 protein from wheat (Riechers et al. 2003). (A) Unsafened (DMSO only) seedling, no primary antiserum (negative control); (B) unsafened (DMSO only) seedling, probed with a 1:500 dilution of primary antiserum raised against TtGSTU1; (C) seedling treated with $10 \mu \mathrm{M}$ fluxofenim safener for $12 \mathrm{~h}$, probed with a 1:500 dilution of primary antiserum raised against TtGSTU1. Red arrows in C mark the massive accumulations of immunoreactive GST proteins in the outermost coleoptile and epidermal cells. Abbreviations: $\mathrm{CL}$, coleoptile; LP, inner leaf primordia. 
and phytoprostanes induce GST activity and the expression of genes related to plant defense and detoxification in sorghum shoot coleoptiles in an analogous manner (Riechers et al. 2018). A cryostat-microtome sectioning method was developed to extract high-quality RNA from the outermost cells of frozen coleoptiles (excluding leaf tissues) for transcript profiling to enrich for safener- and phytoprostane-responsive mRNAs at different time points after treatment (Riechers et al. 2018). Current localization experiments are using an antiserum raised against a specific phiclass sorghum GST isozyme (SbGSTF1) to further investigate tissue-specific expression of different GST subclasses (Labrou et al. 2015) in safener-treated grain sorghum seedling tissues (as shown in Figure 2).

Initial RNA-seq results have identified $>10$-fold increases in transcripts of several detoxification genes, including multiple GSTs, CYPs, and GTs, in safener-treated seedlings compared with untreated controls (unpublished data). Moreover, transcripts encoding proteins related to plant development and defense were highly upregulated by safener, such as enzymes involved in lipid signaling (including OPRs), hormone-related processes (i.e., synthesis of benzoic acid and salicylic acid), or auxin metabolism and homeostasis. Transcripts encoding biosynthetic enzymes possibly involved in chemical defense mechanisms in roots (Cook et al. 2010) and shoots (Busk and Möller 2002; Halkier and Möller 1989) of sorghum seedlings were also strongly induced by safener treatment in coleoptile tissues (unpublished data). These results indicate that safeners may be utilizing signaling pathways and enzymatic mechanisms related to generating allelochemicals (Baerson et al. 2005) or other defense chemicals against abiotic or biotic stresses, as well as upregulating enzymes with the putative function of preventing autotoxicity from these chemicals in sorghum seedlings (Bjarnholt et al. 2018).

\section{Future Research Directions}

Ongoing analyses using bioinformatics and comparative gene expression approaches are aimed at further mining these RNAseq data to provide additional insight into how transcriptional responses are reprogrammed in sorghum coleoptiles following safener treatment (unpublished data). An emerging hypothesis is that safeners regulate a specific, coordinated, and rapid defense and detoxification response in cereal crop seedlings, which includes both up- and downregulation of gene expression. This research helps to elucidate the yet-to-be discovered mechanisms that trigger specific detoxification responses related to safener-regulated protection of cereal crops and, as mentioned previously, may also provide insights into the perplexing question of why safeners do not protect dicot crops from herbicide injury (DeRidder and Goldsbrough 2006; Riechers and Green 2017).

In summary, herbicide safeners are unique organic molecules used for crop protection. Safeners increase the success of commercializing new herbicides by providing a chemical tool to enhance crop tolerance and/or crop-weed selectivity for active ingredients that otherwise might be removed from primary screens due to inadequate crop safety (Riechers and Green 2017), therefore providing an alternative to creating genetically modified crops (Goodrich et al. 2018; Kraehmer et al. 2014). Furthermore, safeners may expand the utility of existing herbicides that do not exhibit adequate crop tolerance without a safener as well as expand our basic knowledge of plant responses to abiotic stresses.
Contributions of Metabolism to Clomazone Activity and Selectivity

Clomazone (Figure 3), a 3-isoxazolidinone, was initially introduced by FMC Corporation in the 1980s for weed management in soybean [Glycine max (L.) Merr.] (Chang et al. 1987). Since that time, use of clomazone (also known in the literature as FMC 57020 and dimethazone) expanded to several additional crops (Anonymous 2018). Clomazone injury manifests itself as bleaching of new leaves (Duke and Kenyon 1986). However, attempts to tie the clomazone mechanism of action to inhibition of phytoene desaturase or steps in the cytoplasmic isoprenoid biosynthesis pathway were unsuccessful (Croteau 1992; Lutzov et al. 1990; Weimer et al. 1992).

Seeking to expand the uses of clomazone shortly after its commercialization, FMC explored the use of safeners. Naphthalic anhydride seed treatment afforded some protection from clomazone injury to corn, but this system was never commercially developed. However, the organophosphate insecticides phorate and disulfoton could protect cotton (Gossypium hirsutum L.) from clomazone injury (Culpepper et al. 2001). This is still a commercial practice. The clomazone label (Anonymous 2018) contains specific language regarding use of the insecticides to protect cotton from clomazone damage: "Do not apply Command $3 \mathrm{ME}$ Herbicide to cotton unless disulfoton or phorate organophosphate insecticide is applied in-furrow with the seed at planting time" and "Failure to apply either disulfoton or phorate insecticides with Command in accordance with in-furrow label use directions can result in crop phytotoxicity (bleaching) and/or stand reduction."

\section{Phorate Effects on Clomazone Injury and Metabolism}

A series of experiments were initiated, in cooperation with FMC, to understand the mechanism of organophosphate safening of cotton from clomazone, and the results were originally published in two articles (Ferhatoglu et al. [2005] and Ferhatoglu and Barrett [2006]). Briefly, the experimental system employed was to place 7-d-old cotton seedlings into hydroponic solution with or without clomazone and with or without phorate. The chlorophyll and carotenoid content of the leaves emerging after the beginning of the treatment was measured $6 \mathrm{~d}$ after the start of the experiment. Complete experimental details are in Ferhatoglu et al. (2005).

Clomazone $(100 \mathrm{nM})$ reduced the levels of both chlorophyll and carotenoids in the new cotton leaves approximately $80 \%$ (Figure 4). Phorate $(50 \mu \mathrm{M})$ partially reversed this reduction, while 0.5 and $5 \mu \mathrm{M}$ phorate were ineffective.
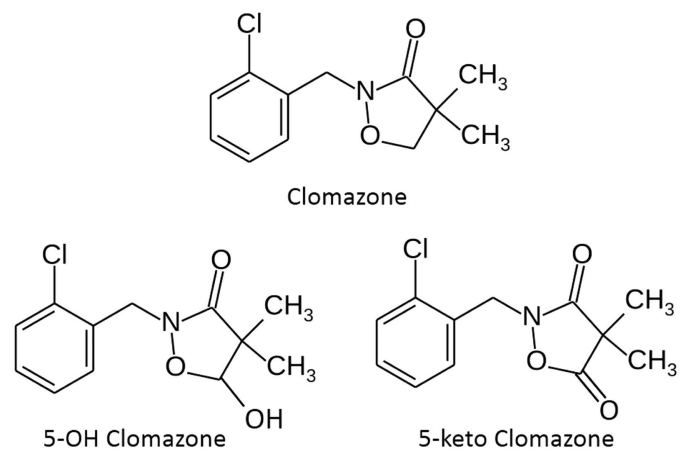

5-keto Clomazone

Figure 3. Structures of clomazone, 5-OH clomazone, and 5-keto clomazone. 


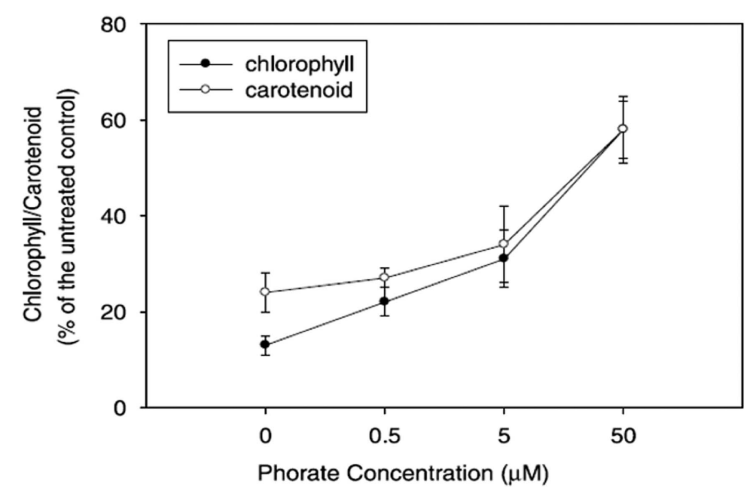

Figure 4. Effect of phorate on chlorophyll and carotenoid levels in new leaves of cotton seedlings treated with $100 \mathrm{nM}$ clomazone for $6 \mathrm{~d}$.

Phorate and other organophosphate insecticides are known inhibitors of CYPs (Baerg et al. 1996; Diehl et al. 1995; Kreuz and Fonne-Pfister 1992; Mougin et al 1991). They can act as herbicide synergists by blocking the CYP-mediated detoxification of an active herbicide molecule (Ahrens 1990; Chample and Shaner 1982).

To test whether phorate affected clomazone metabolism in cotton plants, the roots of cotton seedlings were incubated for $8 \mathrm{~h}$ in $\left[{ }^{14} \mathrm{C}\right]$ clomazone with or without $50 \mu \mathrm{M}$ phorate; this was followed by a 16 -h chase period. The phorate reduced clomazone metabolism in the shoots, but not the roots (Table 1). The phorate treatment had no effect on the unextracted radioactivity. Phorate also reduced clomazone metabolism in excised cotton shoots fed $\left[{ }^{14} \mathrm{C}\right]$ clomazone with or without phorate through the cut stem (Ferhatoglu et al. 2005).

\section{Clomazone Metabolism in Microsomes}

Isolated microsomes are an experimental system that can be used for in vitro studies of pesticide, including herbicide, metabolism by plant CYPs. While cotton microsomes with the capacity to metabolize herbicides had been isolated (Frear 1968; Frear et al. 1969), microsomes isolated from etiolated corn shoots were used. Phorate does reduce the effects of clomazone on chlorophyll and carotenoid levels in new leaves of corn seedlings (Ferhatoglu et al. 2005).

Clomazone metabolism was present in microsomes prepared from etiolated 3-d-old corn seedlings (Ferhatoglu et al. 2005). Three clomazone metabolites eluting at 12.6, 15.4, and $23 \mathrm{~min}$

Table 1. Effect of $50 \mu \mathrm{M}$ phorate on $\left[{ }^{14} \mathrm{C}\right]$ clomazone metabolism in shoots and roots of 7-d-old cotton seedlings. ${ }^{\text {a }}$

\begin{tabular}{lcccc}
\hline & \multicolumn{4}{c}{ Radioactivity $^{\mathrm{b}}$} \\
\cline { 3 - 5 } Tissue & Phorate & Clomazone & Metabolites & Unextracted \\
\hline & & $54 \pm 2$ & $42 \pm 2$ & $9 \pm 4$ \\
\hline Shoot & - & $71 \pm 1^{\mathrm{c}}$ & $27 \pm 10^{\mathrm{c}}$ & $9 \pm 4$ \\
\hline Shoot & + & $45 \pm 4$ & $55 \pm 4$ & $12 \pm 3$ \\
\hline Root & - & $44 \pm 8$ & $56 \pm 8$ & $14 \pm 2$ \\
\hline Root & + & &
\end{tabular}

${ }^{\text {a }}$ Seedling roots in hydroponic solution were exposed to $\left[{ }^{14} \mathrm{C}\right]$ clomazone with and without phorate for $8 \mathrm{~h}$ followed by a 16 -h chase period before extraction.

${ }^{\mathrm{b}}$ Mean \pm SD.

${ }^{\mathrm{C}} \mathrm{A}$ significant difference at $\mathrm{P} \leq 0.05$ compared with the control (no phorate) within the same tissue and within the same column.
Table 2. Induction of $\left[{ }^{14} \mathrm{C}\right]$ clomazone metabolism in corn microsomes by seed treatment with naphthalic anhydride $(0.5 \% \mathrm{w} / \mathrm{w})$, seedling treatment with ethanol $(10 \% \mathrm{v} / \mathrm{v})$, or a combination of the two.

\begin{tabular}{lccc}
\hline \multirow{2}{*}{ Treatment } & \multicolumn{2}{c}{ Clomazone metabolite elution time $^{\mathrm{a}}$} \\
\cline { 2 - 4 } & $12.6 \mathrm{~min}$ & $15.4 \mathrm{~min}$ & $23 \mathrm{~min}$ \\
\hline & $\begin{array}{r}\text { pmol metabolite } \\
\text { protein }^{-1} \mathrm{mg} \mathrm{min}^{-1}\end{array}$ \\
\hline None & $229 \pm 13$ & $55 \pm 10 \mathrm{a}$ & $3 \pm 3 \mathrm{a}$ \\
\hline Naphthalic anhydride & $244 \pm 22$ & $117 \pm 27 \mathrm{~b}$ & $73 \pm 2 \mathrm{~b}$ \\
\hline Ethanol & $261 \pm 31$ & $106 \pm 38 \mathrm{~b}$ & $15 \pm 15 \mathrm{a}$ \\
\hline Naphthalic anhydride plus ethanol & $207 \pm 21$ & $23 \pm 23 \mathrm{a}$ & $42 \pm 5 \mathrm{c}$ \\
\hline
\end{tabular}

${ }^{\text {a }}$ Mean \pm SD. Means within a column followed by different letters are significantly different at $P \leq 0.05$.

were produced in the microsomes (Table 2). Naphthalic induced activity for the metabolites eluting at 15.4 and $23 \mathrm{~min}$ but not at $12.6 \mathrm{~min}$ (Ferhatoglu et al. 2005). The metabolite eluting at 12.6 min was not NADPH dependent, so it is not a product of CYP activity. Production of the metabolite eluting at 23 min was totally inhibited by phorate, while the production of the metabolite at 15.4 was unaffected. This showed that there were two $\mathrm{NADPH}$-dependent clomazone metabolism activities present in the corn microsomes, presumably CYP mediated, and that one was sensitive to phorate inhibition while the other was not. The clomazone metabolite standards 2-chlorobenzyl alcohol and 5-OH clomazone, supplied by FMC, eluted at 15.4 and $23 \mathrm{~min}$, respectively. Therefore, the phorate sensitive activity is presumed to be the production of $5-\mathrm{OH}$ clomazone from clomazone.

The 5-OH clomazone can also cause bleaching in cotton seedlings, reducing both chlorophyll and carotenoid levels in the plants (unpublished data). The 5-OH clomazone was approximately $10 \%$ as toxic as clomazone, which is consistent with data presented by Chang et al. (1987). However, phorate was ineffective as a safener for $5-\mathrm{OH}$ clomazone.

\section{Bioactivation of Clomazone}

From this information, a working hypothesis was formed that phorate inhibited the CYP responsible for the conversion of clomazone to $5-\mathrm{OH}$ clomazone (Figure 3), but phorate was ineffective in preventing the formation of the actual toxicant, 5keto clomazone (Figure 3). This hypothesis was based on the metabolic pathway for clomazone in soybean (El-Naggar et al. 1992), which has multiple pathways for clomazone degradation, including the formation of 5-keto clomazone. In addition, 5-keto clomazone is phytotoxic (Chang et al. 1987). Finally, with the discovery of the plastidic isoprenoid pathway (Lichtenthaler 1999; Lichtenthaler et al. 1997), it was possible to show that 5-ketoclomazone, but not clomazone or 5-OH clomazone, inhibits plant 1-deoxy-D-xylulose-5-phosphate synthase (DXP synthase; Ferhatoglu and Barrett 2006), the first step in this pathway.

\section{Clomazone Selectivity Is Complicated}

In summary, for clomazone to be active, it must be bioactivated to its 5-keto clomazone metabolite to be phytotoxic at its site of action, DXP synthase, the first step in the chloroplastic isoprenoid biosynthesis pathway. The first step in the conversion of clomazone to 5-keto clomazone is the CYP-catalyzed formation of $5-\mathrm{OH}$ clomazone. Organophosphate insecticides such as phorate inhibit 
this process and can safen a crop like cotton from clomazone. While the formation of 5-keto clomazone from 5-OH clomazone is also likely CYP catalyzed, additional studies would be required to establish this. It would also be interesting to test whether CYP inhibitors other than organophosphates could prevent this conversion. It was apparent from this research that phorate, and presumably other organophosphate insecticides, did not prevent the conversion of 5-OH clomazone to 5-keto clomazone, as the insecticide was ineffective as a safener for $5-\mathrm{OH}$ clomazone.

This all means that clomazone selectivity is complicated. The rates of conversion of clomazone conversion to $5-\mathrm{OH}$ clomazone, 5-OH clomazone to 5-keto clomazone, and the conversion of all three of these compounds to their own metabolites will combine to determine how much 5-keto clomazone will be present in a plant and for how long. The clomazone metabolic pathway in tolerant soybean demonstrates this (El-Naggar et al. 1992). More recently, Yasuor et al. (2010) proposed that changes in the rates of the conversion of 5-OH clomazone to dihydroxy-clomazone and clomazone to hydroxymethylclomazone plus 3'-hydroxyclomazone all contribute to clomazone resistance in rice barnyardgrass [Echinochloa phyllopogon (Stapf.) Koss].

\section{Glyphosate Metabolism in Crops and Weeds}

Glyphosate was introduced to the herbicide market in 1974. It has become the most heavily used herbicide in the world, in large part because of the huge success of glyphosate-resistant (GR) crops (Duke 2018). Duke (1988) summarized the literature on glyphosate through the mid-1980s, including its metabolic degradation, and concluded that the evidence for plant metabolism of glyphosate was not conclusive because of the low or no levels of degradation reported, sometimes over long periods of time. Evidence of its degradation by microbes was clear, and it was speculated that reported plant metabolism might have actually been microbial metabolism, either in the plant samples or after extraction. Early work was also limited by difficult analytical methods that have improved with time (Koskinen et al. 2016). It later became unequivocal that many plant species can metabolize glyphosate, especially to aminomethylphosponic acid (AMPA) and glyoxylate (Duke 2011). Indeed, metabolism of glyphosate to AMPA found in microbe-free cell cultures of soybean, wheat, and corn proved that plant cells can metabolize glyphosate (Komoßa et al. 1992). In this system, soybean more readily metabolized glyphosate than did wheat or corn.

The two most commonly reported routes of glyphosate metabolism are to AMPA and glyoxylate by a glyphosate oxidoreductase (GOX) and to sarcosine via a glyphosate C-P lyase. In most cases of plant or microbe metabolism of glyphosate, the only metabolite reported is AMPA. This may be because sarcosine is rarely looked for; however, when it has been sought, it has almost always not been found (e.g., Ribeiro et al. 2015). Metabolism of glyphosate to AMPA has been verified in many plant species now, but the capability for metabolism varies dramatically. For example, Reddy et al. (2008) found a broad range of glyphosate to AMPA metabolism in 11 plant species, ranging from AMPA levels being half, one-fourth, or onesixth the concentration of glyphosate measured in treated tissues $7 \mathrm{~d}$ after application in Illinois bundleflower [Desmanthus illinoensis (Michx.) MacMill. ex B. L. Rob. and Fernald], sicklepod [Senna obtusifolia (L.) H. S. Irwin \& Barneby], and cowpea [Vigna unguiculata (L.) Walp.], respectively, to no detectable AMPA in Italian ryegrass [Lolium perenne L. ssp. multiflorum (Lam.) Husnot], corn, and hemp sesbania [Sesbania herbacea (Mill.) McVaugh]. In that study, each species was treated with the glyphosate rate that inhibited growth $50 \%$, so that differential phytotoxicity of glyphosate was unlikely to account for any differences in metabolism. Later work found that corn did metabolize glyphosate to AMPA when GR corn was treated with full recommended rates, and the AMPA as a proportion of glyphosate was very low at most times after application (Bernal et al. 2012; Reddy et al. 2018). So species that are not reported to metabolize glyphosate may metabolize it very slowly with levels of AMPA too low to detect at specific times after application. GR crops are ideal for studying glyphosate metabolism, because high rates of glyphosate are not phytotoxic, allowing enzymatic degradation to occur unhindered with ample substrate. Glyphosate metabolism in GR soybeans, maize, and canola (Brassica napus L.) has been studied.

Metabolism of glyphosate to AMPA is significant in GR soybean, with levels of $\sim 2$ to 3 and 7 to $25 \mu \mathrm{g}$ of glyphosate and AMPA $\mathrm{g}^{-1}$ of dry harvested seed, respectively, from plants treated with $1.26 \mathrm{~kg}$ ae ha ${ }^{-1}$ of glyphosate at full bloom or $8 \mathrm{wk}$ after planting (Duke et al. 2003). This is not surprising, as glyphosate is phloem mobile, translocating to metabolic sinks such as meristems and developing seeds (Duke 1988). Others have found similar levels of glyphosate and AMPA in seed for GR soybean (Bohm et al. 2014; Bøhn et al. 2014). In another study in which GR soybean was treated with $0.87 \mathrm{~kg} \mathrm{ha}^{-1}$ glyphosate at both 5 and $7 \mathrm{wk}$ after planting, very high levels of glyphosate ( 8 to $\left.15 \mu \mathrm{g} \mathrm{g}^{-1}\right)$ but very little AMPA $\left(\sim 0.1 \mu \mathrm{g} \mathrm{g}^{-1}\right)$ was detected in leaf tissues (Duke et al. 2018). Harvested seed had much lower levels of glyphosate, but relatively more AMPA. Whether the AMPA in the seed was translocated there or was formed by metabolism of glyphosate in the seed is unknown.

GR crops are essentially unharmed by glyphosate at rates recommended for weed management (Nandula et al. 2007). But AMPA is moderately phytotoxic (Hoagland 1980), and GR crops are not resistant to AMPA (Reddy et al. 2004). Thus, if enough AMPA were formed in a GR crop, it might cause phytotoxicity. Under some environmental conditions, farmers have observed moderate chlorosis after treatment of GR soybean with glyphosate (termed "yellow flash" by farmers). This is a transient effect that does not ultimately influence grain yield. In greenhouse studies, this effect was found with AMPA and glyphosate treatments that resulted in the same in vivo AMPA concentrations, whether from AMPA or glyphosate treatment (Reddy et al. 2004). These results suggest that yellow flash is due to accumulation of sufficient AMPA for noticeable chlorosis.

GR corn metabolizes glyphosate to AMPA, but at a much lower rate than GR soybean does (Bernal et al. 2012: Reddy et al. 2018). The first GR canola commercially grown was the only GR crop that contained a transgene for a microbial GOX, in addition to a gene for a microbial GR 5-enolpyruvylshikimate-3-phosphate synthase (EPSPS), the target of glyphosate (Green 2009). Very little glyphosate is converted to AMPA in non-GR canola, whereas virtually all of the glyphosate applied to GR canola is converted to AMPA within $7 \mathrm{~d}$, when glyphosate is supplied in small amounts (Corrêa et al. 2016) (Figure 5). Only AMPA and no glyphosate was found in untreated leaves of treated plants. Whether the AMPA was translocated to untreated leaves or formed by glyphosate metabolism in those leaves was not determined. The relative contributions to resistance of the GOX and GR EPSPS genes are unknown in GR canola, but current commercial varieties of GR canola contain only a GR EPSPS transgene, as do all other GR crops. Thus, whether the canola GOX gene alone would provide adequate resistance for a commercial GR crop is unknown. 

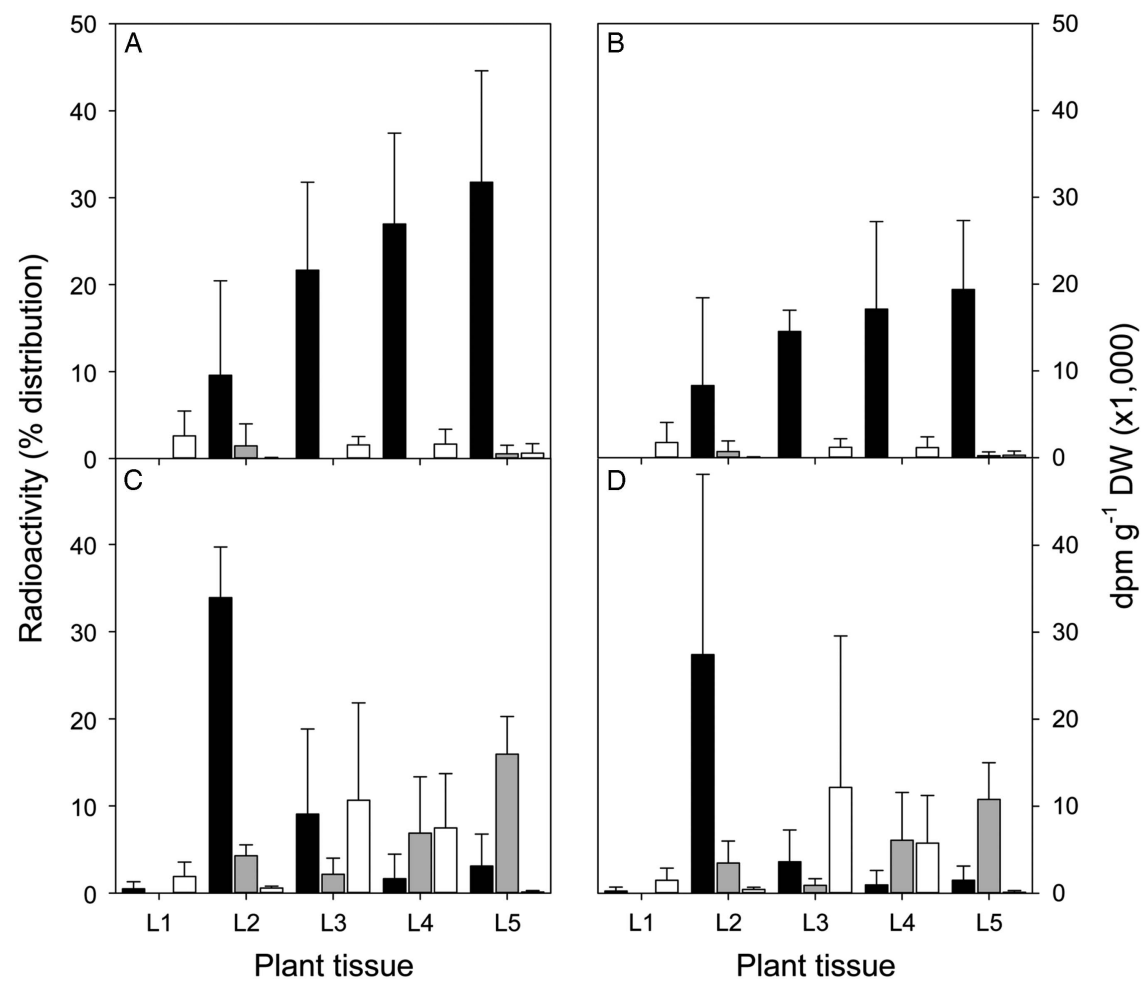

Figure 5. Metabolism of $\left[{ }^{14} \mathrm{C}\right]$ glyphosate 1 DAT in conventional (A, B) and glyphosate-resistant canola (C, D). The data are expressed as percent distribution of total radioactivity in each leaf on the left side and as actual disintegrations per minute per gram dry weight (dpm $\mathrm{g}^{-1} \mathrm{DW}$ ) of the leaves on the right. Black bars, glyphosate; gray bars, AMPA; white bars, unknown metabolite(s). Error bars are \pm 1 SE. With permission from Corrêa et al. (2016).

Several glyphosate metabolism transgenes have been proposed for generation of GR crops. These include transgenes for an engineered bacterial oxidase (Nicolia et al. 2014), a modified bacterial glyphosate acetyltransferase (GAT) (Siehl et al. 2007), and a decarboxylase-type enzyme that inactivates glyphosate (Hammer et al. 2007). None of these transgenes have been used in commercial GR crops, although the GAT genes came close to commercialization (Green 2009).

Two generalizations can be made from existing glyphosate metabolism literature regarding glyphosate metabolism in non-transgenic plants. Legumes tend to have higher rates of glyphosate metabolism than other species, and Poaceae species usually have very low rates of metabolism. However, no methodical, systematic survey exists that uses a consistent experimental design and reliable assay methods of the capacity for glyphosate metabolism in a wide range of taxonomically diverse plant species.

Glyphosate is nonselective, but some species are more tolerant than others. Because glyphosate is perhaps the slowest-acting commercial herbicide, the plant has more time to metabolize it before severe toxicity occurs. Thus, rapid metabolism could be a tolerance mechanism. However, there is no good evidence that this is the case. The ability to metabolize glyphosate did not correlate well with the glyphosate $\mathrm{I}_{50}$ values for 10 species (Reddy et al. 2008), although it was speculated that it might contribute to tolerance in some species. A problem with this study is that glyphosate and AMPA were determined at only one point in time after glyphosate application. The dynamics of metabolism are highly likely to vary between species, so determination of the proportion of glyphosate metabolized over a critical period for herbicide damage would be needed to better evaluate the role of metabolism in producing tolerance.
Morningglory species (Ipomoea spp.) are among the most glyphosate-tolerant weeds. Although there is no proof of evolved resistance (Heap 2018), some claims have been made without conclusive evidence (e.g., Debban et al. 2015). Glyphosate tolerance of pitted morningglory (Ipomoea lacunosa L.) biotypes varied by as much as 2.6-fold, but this was not explained by differential metabolism (Ribeiro et al. 2015). The most and least susceptible biotypes both readily metabolized glyphosate to AMPA at about the same rate, but there was differential translocation that was consistent with the differences in susceptibility.

Clearly, many plant species have a means of metabolizing glyphosate to AMPA. Considering the tremendous selection pressure that has resulted in several mechanisms of evolved resistance to glyphosate (Sammons and Gaines 2014), one would expect the enzyme(s) responsible for AMPA production to be selected for, either to produce a mutated enzyme with greater efficiency as a GOX or to generate greater amounts of GOX enzyme. In their review, Sammons and Gaines state that metabolism of glyphosate in plants is rare and are skeptical of reports that metabolism is involved in reported resistance of sourgrass [Digitaria insularis (L.) Mez ex Ekman] and horseweed (Erigeron canadensis L.) to glyphosate, partly by conversion to sarcosine (de Carvalho et al. 2012; Gonzalez-Torralva et al. 2012b). Similar results were reported by some of the same authors for glyphosate tolerance of velvet bean [Mucuna pruriens (L.) DC.] (RojanoDelgado et al. 2012). These papers are unusual, both in reporting sarcosine and glyoxylate as plant metabolites of glyphosate and by invoking metabolism as a resistance mechanism. Both sarcosine and glyoxylate are plant metabolites that can be found in untreated plants, so without ${ }^{14} \mathrm{C}$-labeling of these compounds from $\left[{ }^{14} \mathrm{C}\right]$ glyphosate, the results are inconclusive. However, they detected AMPA, a compound absent in plants not treated with 
glyphosate, to support their claims. Using $\left[{ }^{14} \mathrm{C}\right]$ glyphosate, others have found no metabolism of glyphosate in either susceptible or resistant E. canadenesis or hairy fleabane (Erigeron bonariensis L.) (Feng et al. 2004; Dinelli et al. 2006, 2008). Sammons and Gaines (2014) did not include glyphosate metabolism as a proven mechanism of evolved resistance to glyphosate.

More rapid metabolism of glyphosate in GR weeds has been searched for without result in many papers looking for the mechanism of glyphosate resistance. For example, although there were no statistical differences in AMPA found in susceptible and two GR A. palmeri biotypes, the resistant biotypes tended to have more metabolism than the susceptible biotypes (Nandula et al. 2012). However, none of the biotypes accumulated much AMPA at $7 \mathrm{~d}$ after treatment, with AMPA not reaching $1 \%$ of the glyphosate levels found in the tissues, except in the susceptible biotype treated with a very low $\mathrm{I}_{50}$ rate $\left(90 \mathrm{~g} \mathrm{ha}^{-1}\right)$.

There are still important, unanswered questions about glyphosate metabolism in plants, including the nature of the enzyme(s) that metabolizes glyphosate to AMPA. Glycine oxidases from microbes can act as a GOX enzyme (e.g., Pollegioni et al. 2011). At least some legumes can oxidize glycine in nodules via a leghaemoglobinassociated reaction (Lehtovaara 1978). But, nonnodulated species and leaf tissues of legumes can convert glyphosate to AMPA and glyoxylate. D-amino acid oxidase from Bradyrhizobium japonicum can also oxidize glyphosate to AMPA and glyoxylate, and the transgene for this enzyme can provide glyphosate resistance to Arabidopsis thaliana L. (Han et al. 2015). However, equivalent glycine and D-amino acid oxidases have not been identified in plants. The clear ability of some plant species to oxidize glyphosate to AMPA indicates that they have an enzyme similar to these microbial enzymes. The enzymatic or other potential mechanisms of glyphosate conversion to AMPA are still a mystery.

An alternative explanation to direct metabolism of glyphosate by plants is that some plants might have endophytes that can metabolize glyphosate. Evidence is growing that endophytes can contribute to metabolic degradation of herbicides (Tétard-Jones and Edwards 2016), and some plant-associated microbes can clearly metabolize glyphosate (e.g., Kryuchkova et al. 2014). The soybean endophyte Burkholderia gladioli is resistant to glyphosate (Kuklinsky-Sobral et al. 2005), but whether this is due to metabolism is unknown. There is no available proof of any endophyte-mediated glyphosate metabolism in planta. Endophyte infection increases with glyphosate resistance in L. perenne (Handayani et al. 2017), but glyphosate metabolism in the populations was not determined, and metabolism has been found to be very low and uninvolved in Lolium perenne ssp. multiflorum resistance to glyphosate in other places in the world (Barroso et al. 2018; Gonzalez-Torralva et al. 2012a). It is possible that there has been horizontal gene transfer of a gene for an enzyme with GOX activity. But, it does not appear that the extreme selection pressure caused by glyphosate in recent decades has caused this to occur, as metabolism is not a firmly established mechanism of weed resistance to glyphosate. This supports the view that horizontal gene transfer from microbes to plants is not a common occurrence.

\section{Bioactivation of Natural Phytotoxins: The Exception or the Rule?}

\section{Evolution of Bioactive Natural Products}

Within ecosystems, plants cohabit in association with a wide variety of microorganisms, insects and nematodes, and other plants. These constant multitrophic interactions have led to the coevolution of positive interactions such as mutualistic and symbiotic relationships and negative interactions such as competitive and parasitic relationships. Within this context, pathogens have adapted to their plant hosts by deploying virulence proteins that either suppress plant immune responses or increase plant susceptibility. Plant-pathogen interactions also involve a form of chemical warfare derived from novel metabolic pathways (Schueffler and Anke 2014) that aims at strategically using one's opponent's weakness to one's benefit (Maor and Shirasu 2005; Verhoeven et al. 2009). There is great interest in using these natural phytotoxins to develop new herbicide chemical classes or discover novel mechanisms of action (Duke and Dayan 2015).

These secondary metabolic pathways evolve through gene duplication. This slow evolutionary process most often leads to loss of function of the duplicated genes (pseudogenization), but it occasionally leads to a beneficial gain of a new function (neofunctionalization) (Moore and Purugganan 2005). Over time, this has resulted in a vast array of structurally diverse biologically active molecules (Flagel and Wendel 2009; Ober 2005). This evolutionary process is similar to the high-throughput screens developed by all major agrochemical companies searching for new herbicides. While conventional in vitro screens test a large number of compounds on a single enzyme target very rapidly, natural high-throughput processes allow for the identification and customization of molecules that optimize their in vivo activities. More than 200,000 secondary metabolites have been characterized, and it is anticipated that many more will be discovered (Clevenger et al. 2017).

Natural phytotoxins are typically small molecules that explore chemical spaces not covered by herbicides obtained through the usual organic synthetic approaches. Many of these chemicals have novel mechanisms of action that target enzymes and/or pathways that also exist in the organisms producing them. Consequently, these molecules are often synthesized and/or stored as inactive protoxins that are bioactivated in the target organisms. Bioactivation may take different forms, such as removing protective groups or adding functional groups. Alternatively, some organisms produce the phytotoxins in their active forms but protect themselves from autotoxicity by sequestering them in subcellular compartments or specialized cells (Figure 6). A few examples of the various mechanisms of bioactivation are examined in the following sections.

\section{Bioactivation by Removing Protective Groups}

Some organisms produce toxins as protoxins that possesses additional groups to protect themselves from autotoxicity. This is often necessary, because these organisms have enzymes that are sensitive to the toxin they produce. The conversion of the protoxin bialaphos to the herbicidal L-phosphinothricin, the active

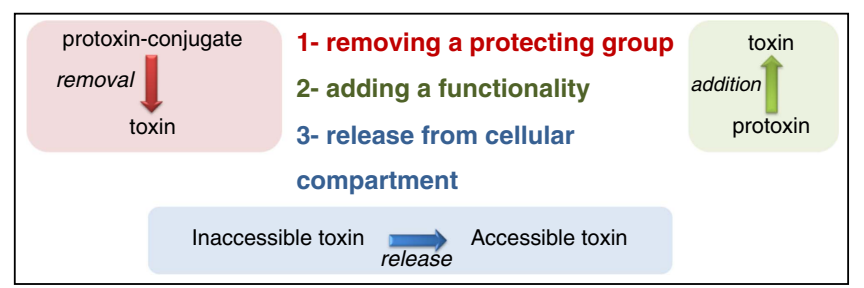

Figure 6. Various strategies used by organisms that produce protoxins requiring bioactivation before interacting with their respective target sites. 
enantiomer of glufosinate, is perhaps the most well-known and relevant example of bioactivation via cleavage of protective groups (Figure 7A). Bialaphos is a tripeptide (L-alanyl-L-alanyl-phosphinothricin) produced by the soil bacteria Streptomyces hygroscopicus and Streptomyces viridochromogenes. This metabolite is very rapidly bioactivated in planta by removing two alanine residues to release $\mathrm{L}$-phosphinothricin. Phosphinothricin is a potent inhibitor of glutamine synthetase (Wild and Ziegler 1989), a key enzyme responsible for glutamine biosynthesis and ammonia detoxification. Organisms producing bialaphos also have specific acetylases that rapidly deactivate L-phosphinothricin as another mechanism of protection against the toxic effect of this bioactive natural product. Another common bioactivation by cleavage involves the removal of glycosides by glucosidases to release herbicidal aglycones, such as is observed with podophyllotoxin produced by the plant belonging to the Podophyllum genus. Podophyllotoxin is an aryltetralin lignin that acts as a natural mitotic inhibitor. While this molecule is used as a precursor for the semisynthesis of several anticancer pharmaceutical drugs because of its antimitotic activity, podophyllotoxin would cause great damage to the plants producing it. Consequently, mayapple (Podophyllum peltatum L.) conjugates podophyllotoxin with a glucose and stores it within the vacuole, preventing it from interacting with the physiologically active cytosol and interfering with numerous microtubule-driven processes. Interestingly, there is a glucosidase present in the cytosol with high specificity for podophyllotoxin-O-glucoside that is mostly inactive at physiological $\mathrm{pH}$ of 7 but has its greatest activity at $\mathrm{pH} 4$ (Dayan et al. 2003). These biochemical characteristics suggests that this glucosidase would be recruited for the hydrolysis of the glucoside to release the active aglycone upon injury to the leaf, which would cause the $\mathrm{pH}$ to drop as the large volume of the vacuole mixes with the cytoplasm.

\section{Bioactivation by Adding Functional Groups}

Other organisms produce toxins as protoxins that require the addition of functional groups to activate the structures. Some strains of Fusarium solani produce 2,5-anhydro-D-glucitol, a sugar analogue that requires bioactivation to exert activity on its target site (Dayan et al. 2002). 2,5-Anhydro-D-glucitol has no known biological activity. However, up to milllimolar concentrations of this molecule is released by $F$. solani as it invades a plant. Through the process of coevolution this pathogen has exploited the biochemical machinery of its host plant to bioactivate 2,5-anhydro-D-glucitol into a phytotoxin. 2,5-Anhydro-Dglucitol is a sugar analogue that serves as a substrate for two glycolytic kinases endogenous to the host plant (namely hexokinase and phosphofructokinase) (Figure 7B). The biochemical functions of these kinases have been exploited to produce a diphosphate derivative of 2,5-anhydro-D-glucitol. This bioactivated toxin acts as a substrate analogue that inhibits fructose-1,6diphosphate aldolase, a key step in glycolysis (Dayan et al. 2002).

This type of protoxin bioactivation occurs by hijacking native plant kinases to produce active phosphorylated phytotoxins. For example, certain strains of $S$. hygroscopicus produce hydantocidin. Upon phosphorylation, hydantocidin becomes an analogue of inosine monophosphate, which is a potent inhibitor of adenylosuccinate synthetase, an enzyme involved in purine biosynthesis (Fonne-Pfister et al. 1996). Similarly, carbocyclic coformycin is a protoxin produced by Sacchavothvix spp., whose mechanism of action requires phosphorylation of its $5^{\prime}$-hydroxy group to
A

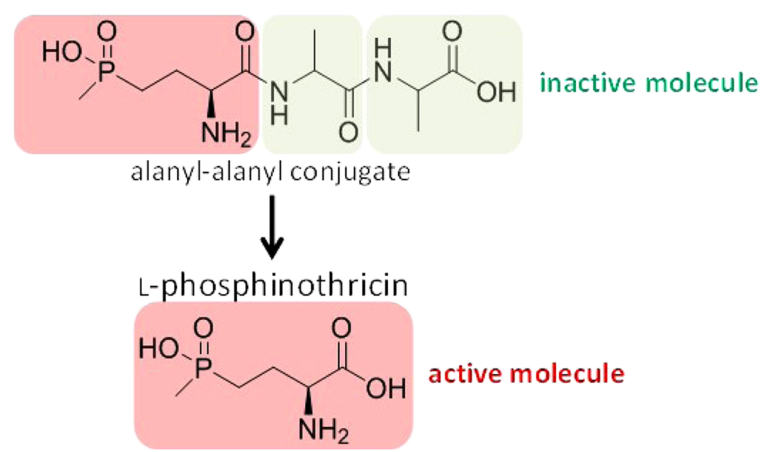

B

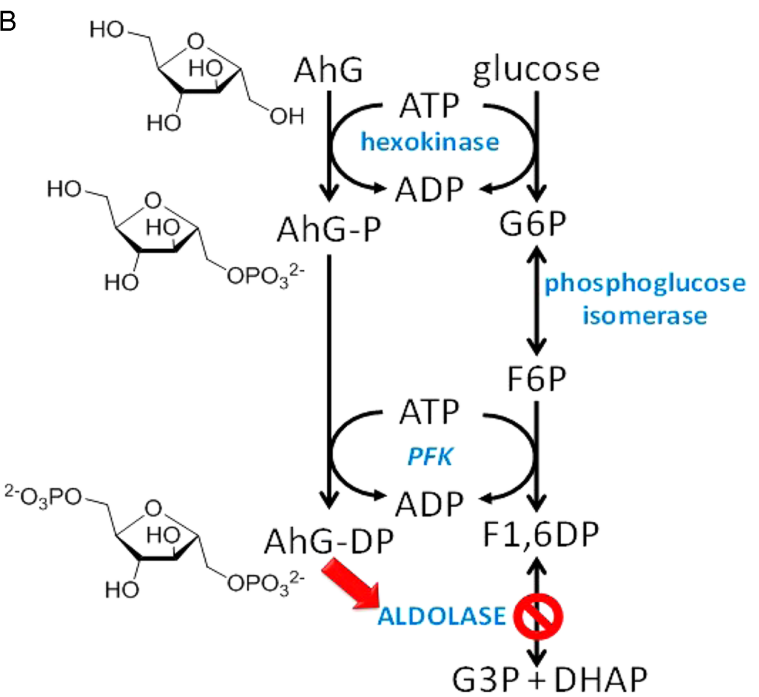

Figure 7. (A) Example of bioactivation of a protoxin by removal of a protective group. Removal of the alanyl-alanyl conjugate from the inactive protoxin bialaphos produced by Streptomyces hygroscopicus to release the active molecule I-phosphinothricin, a potent inhibitor of plant glutamine synthetases. (B) Example of hijacking of plant biochemical machinery to bioactivate a protoxin by adding an active functionality. Phosphorylation of 2,5-anhydro-D-glucitol produced by Fusarium solani NRRL 18883 via the action of the plant hexokinase and phosphofructokinase, leading to the formation of a fructose-1,6-diphosphate analogue inhibitor of aldolase. Abbreviations: AhG, 2,5-anhydro-D-glucitol; DHAP, dihydroxyacetone phosphate; F-1,6-DP, fructose-1,6-diphosphate; F6P, fructose-6-phosphate; G3P, glyceraldehyde 3-phosphate; G6P, glucose-6-phosphate; PFK, phosphofructokinase.

produce an irreversible inhibitor of adenosine monophosphate deaminase (Dancer et al. 1997).

\section{Bioactivation by Altering the Shape of a Phytotoxin}

Sometimes, protoxins can be bioactivated as the result of more subtle changes. For example, the gram-negative $\beta$-proteobacteria Burkholderia sp. A396 produces large amount of romidepsin, a 16membered cyclic depsipeptide bridged by a 15 -membered macrocyclic linked via a disulfide bridge. Reduction of the disulfide bridge is catalyzed in planta by native enzymes and opens up the 15membered macrocyclic structure to release a long side chain. This increases the potency of romidepsin on plant histone deacetylases.

\section{Bioactivation by Release from Cellular Sequestration}

Not all natural phytotoxins require bioactivation. In these cases, the metabolites are already highly toxic, and organisms have devised schemes to protect themselves from the lethal effect of 
these compounds by compartmentalizing or exuding them. For example, leptospermone is a metabolite produced by several plant species (e.g., Callistemon spp., Leptospermum spp., and Eucalyptus spp.). This molecule and several other analogues produced by these plants are potent inhibitors of $p$-hydroxyphenylpyruvate dioxygenase (HPPD) (Dayan et al. 2007). In fact, leptospermone served as a template for the development of HPPD-inhibiting herbicides (Beaudegnies et al. 2009). This $\beta$-triketone natural product is produced exclusively in schizogenous glands (Figure 8A). This allows the production of a potent toxin in a cellular compartment isolated from the rest of the physiologically active portion of the plant that possesses endogenous HPPD enzyme sensitive to its own toxin.

As another example, sorgoleone is produced in most of the species in the Sorghum genus. This lipid benzoquinone is a potent photosystem II (PSII) inhibitor and competes for the binding site of plastoquinone on the Qв binding site in fashion similar to the herbicide atrazine (Gonzalez et al. 1997). Isolated chloroplasts of sorghum are just as sensitive to sorgoleone as other plant species. However, sorghum is able to produce large amounts of this toxin by compartmentalizing its biosynthesis to specialized root hair cells that rapidly exude it from the root into the rhizosphere (Dayan et al. 2009) (Figure 8B). Because sorgoleone does not translocate from the root to the foliage, sorghum remains uninjured while repressing the growth of small-seeded weeds germinating within its rhizosphere.

\section{Bioactivation of Natural Phytotoxin-The Exception or the Rule?}

The short review above clearly shows that many phytotoxins are produced as protoxins or must be sequestered by the producing

A

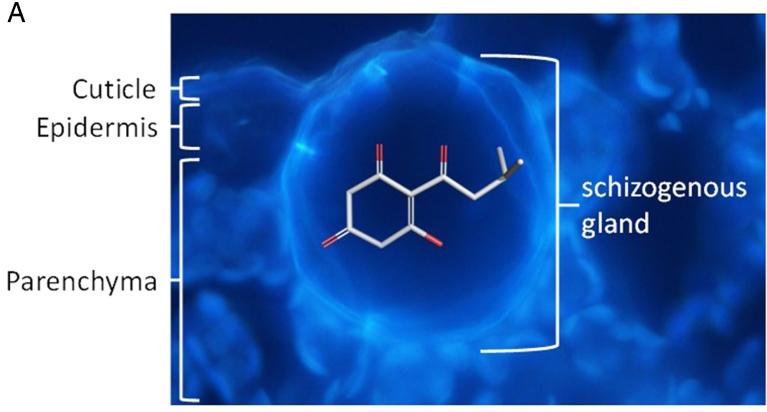

B

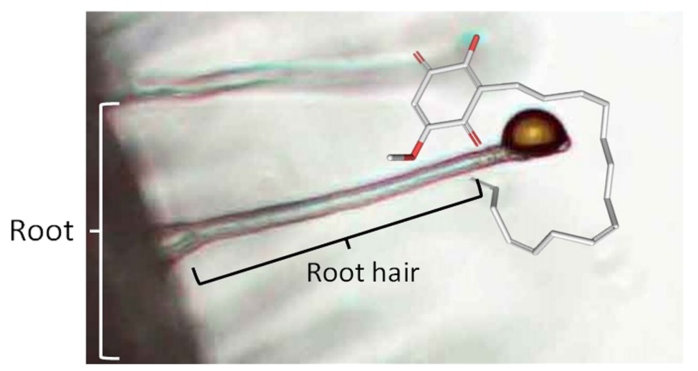

Figure 8. Examples of cellular compartmentalizations. (A) Leptospermone is a potent p-hydroxyphenylpyruvate dioxygenase (HPPD) inhibitor produced by a number of plant species, including Callistemon spp., Leptospermum spp., and Eucalyptus spp. This natural $\beta$-triketone is a potent inhibitor of HPPD. Plants produce it in specialized glands isolated from the rest of the cells to avoid autotoxicity problems. (B) Sorgoleone is a potent phytotoxin produced by most members of the Sorghum genus. This lipid benzoquinone is produced exclusively in root hairs and exuded into the rhizosphere. organism to avoid autotoxicity. This is particularly true if the pathogen producing the toxin possess the enzyme target site affected by the active form of the toxin. These complex systems are the results of coevolution between plant biotic interactions that cannot be achieved by the current approaches used by the agrochemical industry. As to whether bioactivation of natural phytotoxins is the exception or the rule, it is difficult to make a definitive statement. Many toxins are active in themselves and do not require bioactivation. However, evolutionary forces have clearly identified processes that can be hijacked to bioactivate certain molecules. These processes enable organisms to produce protoxins that will only be active in the target organism.

\section{Glutathione Transferases Associated with Non-Target Site Resistance to Herbicides in Alopecurus myosuroides}

GSTs (EC 2.5.1.18) are a superfamily of detoxifying enzymes that have evolved into six discreet clades classified as the zeta, theta, phi, tau, lambda, and dehydroascorbate reductase classes in plants (Dixon and Edwards 2010). GSTs from the tau (GSTU) and phi (GSTF) classes have long been associated with herbicide tolerance and selectivity in crops through their ability to rapidly conjugate and detoxify a range of chemistries (Cummins et al. 2011). Normally, the expression of GSTs is an order of magnitude lower in weeds than in crops, leading to a corresponding reduced ability to detoxify herbicides (Dixon and Edwards 2010). Repeated selection with herbicides can lead to enhanced GST expression in weeds, leading in turn to resistance. Consistent with this, transcripts encoding GSTFs and GSTUs have been recently identified as being enhanced in populations exhibiting non-target site herbicide resistance (NTSR) in several weed species; notably wild oat (Avena fatua L.) (Keith et al. 2017), American sloughgrass [Beckmannia syzigachne (Steud.) Fernald] (Pan et al. 2016), shortawn foxtail (Alopecurus aequalis Sobol.) (Zhao et al. 2017), annual ryegrass (Lolium spp.) (Duhoux et al. 2017a), and A. myusuroides (TétardJones et al. 2018). Recent studies have demonstrated that the enhanced expression of GSTs able to conjugate and detoxify atrazine is responsible for evolved resistance to this herbicide in populations of $A$. palmeri (Nakka et al. 2017a) and A. tuberculatus (Evans et al. 2017). However, in A. myusuroides and A. fatua, the GSTs upregulated in the NTSR populations have little activity toward herbicides, even though their enhanced expression is intimately linked to resistance (Burns et al. 2017; Cummins et al. 1999). Recent studies in A. myosuroides demonstrated that the phi AmGSTF1, which has little conjugating activity toward herbicides, was uniquely associated with all NTSR populations identified to date (Tetard-Jones et al. 2018). Overexpression of AmGSTF1 in Arabidopsis (A. thaliana ecotype Columbia-0), enhanced tolerance to several herbicides, notably those that did not undergo glutathionylation in the course of their detoxification (Cummins et al. 2013; Tétard-Jones et al. 2018). This suggested that GSTs must possess alternative NTSR protective activities that do not directly involve herbicide detoxification. However, it is known that the complex NTSR trait in different weed species is multigenic (Duhoux et al. 2017b; Keith et al. 2017; Tétard-Jones et al. 2018), suggesting that a single GST cannot confer multiple resistance. In further investigating the roles of these proteins in NTSR, we now report the detailed characterization of the all detectable GSTs (the "GSTome"), associated with herbicide resistance using a combination of transcriptomics, proteomics, and functional expression of the respective recombinant enzymes. 


\section{Analysis of AmGSTF1 Variants in Alopecurus myosuroides}

Recent proteomic studies confirmed the presence of elevated levels of the phi A. myosuroides AmGSTF1 polypeptides in multiple NTSR populations, as compared with herbicide-sensitive (HS) populations (Tétard-Jones et al. 2018). Closer examination of the AmGSTF1 polypeptides revealed they were derived from two of the four known isoforms (Supplementary Figure S1), namely the c and $\mathrm{d}$ variants, previously identified in the screening of a cDNA expression library prepared from the NTSR A. myosuroides population, 'Peldon' (Cummins et al. 1999). Whereas only the c and $\mathrm{d}$ variants were expressed as polypeptides, analysis of the transcriptomic data showed that all four isoforms were present as mRNAs in NTSR A. myosuroides (Tétard-Jones et al. 2018). Differences were observed in the relative abundance of the AmGSTF1 transcripts, with the $\mathrm{c}$ form generally more abundant in leaves and the $\mathrm{d}$ form dominant in the stems. Previous enzymatic and transgenic studies have exclusively concentrated on the characterization of the AmGSTF1c isoform (Cummins et al. 2013). As the proteomic studies now showed that alternative isoforms were also being expressed (Tétard-Jones et al. 2018), it was clearly important to determine whether the variants were all functionally equivalent. AmGSTF1a was selected for comparative enzymatic analysis with AmGSTF1c, as the most variant isoform (Supplementary Figure S1). The GST sequences were then subcloned into the pET-STRP3 vector and expressed as Strep-tag II fusion proteins in Escherichia coli (Dixon et al. 2009). The affinitypurified enzymes were then assayed for glutathione transferase and glutathione peroxidase (GPOX) activity, with the enzymes showing similar activities and kinetic constants (Supplementary Table S1). It was concluded that while AmGSTF1 is present as multiple isoenzymes in A. myosuroides, the isoenzymes are functionally identical and, as such, all further references to AmGSTF1 refer to the $\mathrm{c}$ isoform.

\section{GST Genes Expression in NTSR Alopecurus myosuroides}

To identify the full range of GST genes associated with NTSR in A. myosuroides, the respective transcriptome contig sequences of NTSR ('Peldon') as compared with the HS ('Rothamsted') populations reported previously were examined (Tétard-Jones et al. 2018). Using this approach, a total of 53 contigs corresponding to GST genes were identified and analyzed by Blast (BlastX) searches against the respective translated proteome database (Tétard-Jones et al. 2018). This approach clustered the contigs into 15 distinct GSTs, which on online protein blast (BlastP) analysis, yielded eight GSTUs, six GSTFs, and one lambda (L) GSTL gene (Supplementary Table S2). Of the phi GSTs, isoforms of the previously undescribed AmGSTF2 and AmGSTF3 genes were identified in addition to AmGSTF1. Of the eight GSTU genes, one sequence corresponded to AmGSTU1 (Cummins et al. 2009). The remaining new unigenes were named AmGSTU2 to AmGSTU7, of which AmGSTU2 was the most highly represented in the NTSR populations (Tétard-Jones et al. 2018).

AmGSTU2 was selected for further characterization, with multiple sequence variants, termed AmGSTU2a-f, recovered from the Peldon cDNA library (Cummins et al. 1999). Phylogenetic analysis identified orthologues in wheat, maize, and barley (Hordeum vulgare L.). The phylogenetic analysis showed that AmGSTU2a and AmGSTU2b (95\% similarity) were most likely derived from a lineage-specific duplication (Figure 9). Both were members of a clade, also containing AmGSTU1, that is unique to monocots (Brazier-Hicks et al. 2018). In contrast, AmGSTU3 to AmGSTU7 were more evolutionarily diverse, sharing protein sequence identities ranging from $36 \%$ to $76 \%$ and aligning to several distinct tau class clades (Figure 9). Of the 15 upregulated GST genes, AmGSTU2a was the most abundant at both transcript and expressed protein levels (Tétard-Jones et al. 2018; Figure 10); as such, it was selected for further characterization. The coding sequence of AmGSTU2a was isolated by PCR from the Peldon cDNA library and expressed as the respective Strep-tag II fusion protein in E. coli. Enzyme activity assays of the recombinant protein showed that while AmGSTU2a conjugated 1-chloro-2,4dinitrobenzene and the herbicides fenoxaprop-ethyl and metolachlor, it was inactive as a GPOX (Table 3). Similarly, the related AmGSTU1 from A. myosuroides and an orthologue TaGSTU4 (69\% identity) in wheat (Thom et al. 2002), also showed activity toward multiple herbicides, suggesting this clade of tau GSTs is important in detoxification.

\section{GST Protein Expression in Alopecurus myosuroides}

Proteomics was used to monitor changes in the GSTome in NTSR populations either derived from different geographical locations in the United Kingdom (Peldon, 'Essex', and 'Oxford') or by repeated selection with the herbicides pendimethalin or fenoxaprop as compared with HS plants (Tétard-Jones et al. 2018). While 15 distinct GSTs showed induced transcriptional expression, only four of these genes were accompanied by increased protein expression as determined by differential two-dimensional proteomics of stem and leaf tissue (Figure 10). In the leaves, the $c$ and d isoforms of AmGSTF1 were the most highly abundant GSTs detected by proteomics (Figure 10). In the case of AmGSTU2, the 140-fold enhancement in transcripts in the stems of Peldon versus HS plants was associated with only a 6-fold increase in the respective protein abundance. In the stem tissue, the enhancement of AmGSTF2, AmGSTU2, and the AmGSTF1c/ $\mathrm{d}$ isoforms in the NTSR Peldon, Oxford, and 'pendimethalin' populations, was clearly distinct from that determined in the plants selected on fenoxaprop (Figure 10). This suggested that the GSTome associated with NTSR in A. myosuroides could vary depending on the history of herbicide selection.

As GSTUs and GSTFs are associated with a wide range of plant stress responses (Dixon and Edwards 2010), it was then of interest to determine whether the NTSR-associated GSTs were perturbed by biotic and abiotic stress in A. myosuroides. As described previously (Tétard-Jones et al. 2018), HS plants were exposed to a range of stress treatments, including wounding, heat, and drought, along with exposure to the herbicide safener cloquintocet mexyl. The results demonstrated that the changes in the GSTome associated with NTSR could not be replicated by any of the stresses, with the abundance of AmGSTU2 actually suppressed by these treatments (Figure 10).

\section{Conclusions on the Roles of GSTs in NTSR Alopecurus myosuroides}

A characteristic feature of the GSTs induced by NTSR was their relative abundance and multiplicity in isoforms identified in the transcriptome studies, as compared with the proteome experiments. While the major phi AmGSTF1 was encoded by at least four sequences (a to $\mathrm{d}$ isoforms) and the tau AmGSTU2 by six open reading frames (a to $\mathrm{f}$ isoforms), at the level of protein 


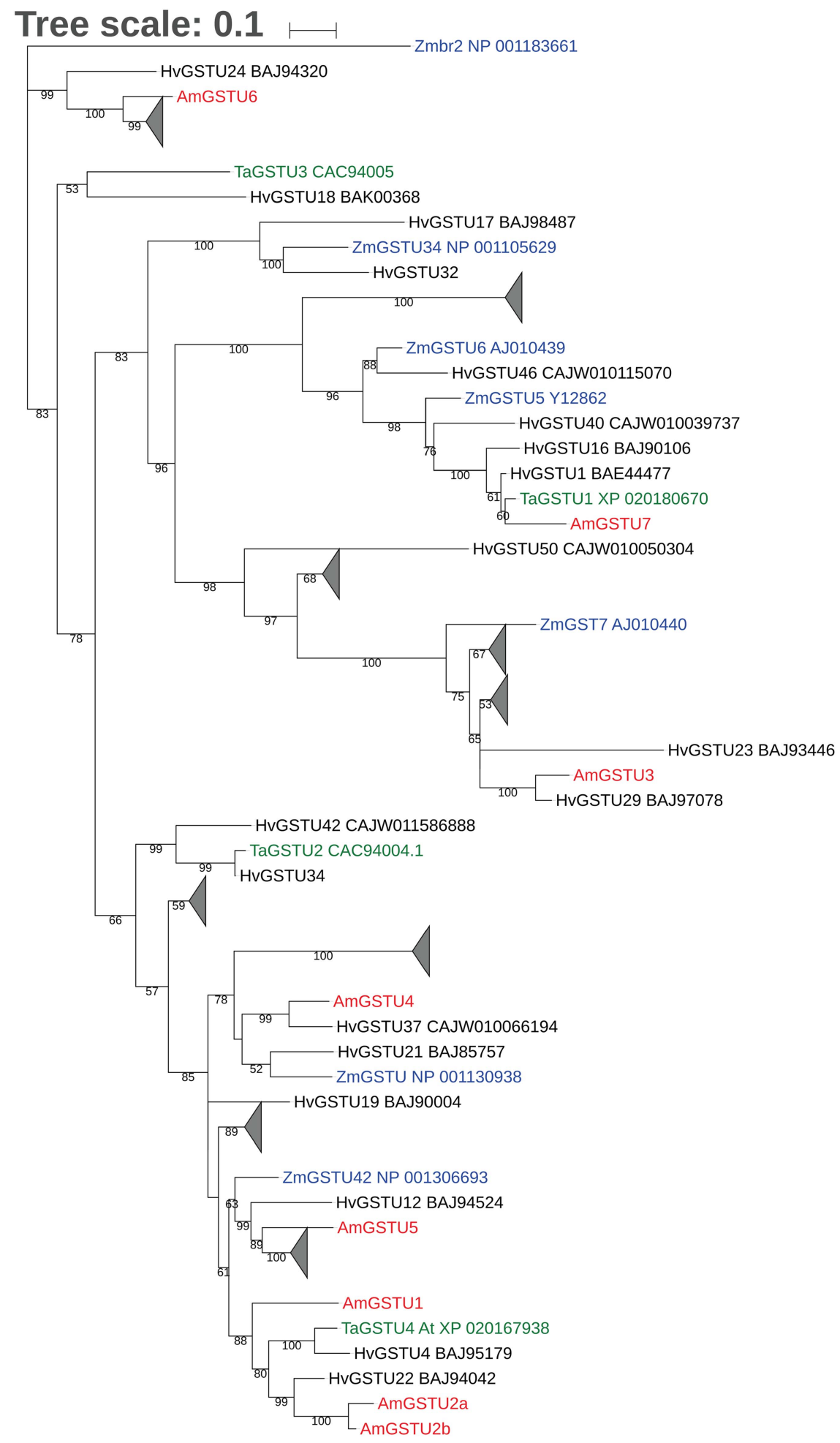

Figure 9. Phylogenetic analysis of tau class of glutathione S-transferase (GSTUs) proteins in grass weeds and crop plants. Amino acid sequences of GSTUs from Alopecurus myosuroides (red), barley (black), wheat (green), and maize (blue) were used for maximum-likelihood alignment for phylogenic analysis. The number on the branch represents the bootstrap support values above $50 \%$. The scale bar indicates the inferred number of substitutions per site. Clades comprising exclusively barley sequences were collapsed into triangles.

expression they were represented by only two and one isoforms, respectively (Figure 10). Similarly, the relative enhancement of the transcripts encoding these GSTs was at least an order of magnitude greater than the changes determined in the abundance of the respective proteins (Figure 10). The discrepancy between transcriptome and proteome data for the GSTs demonstrates that the respective genes are subject to major posttranscriptional regulation either at the mRNA level or during translation or protein 


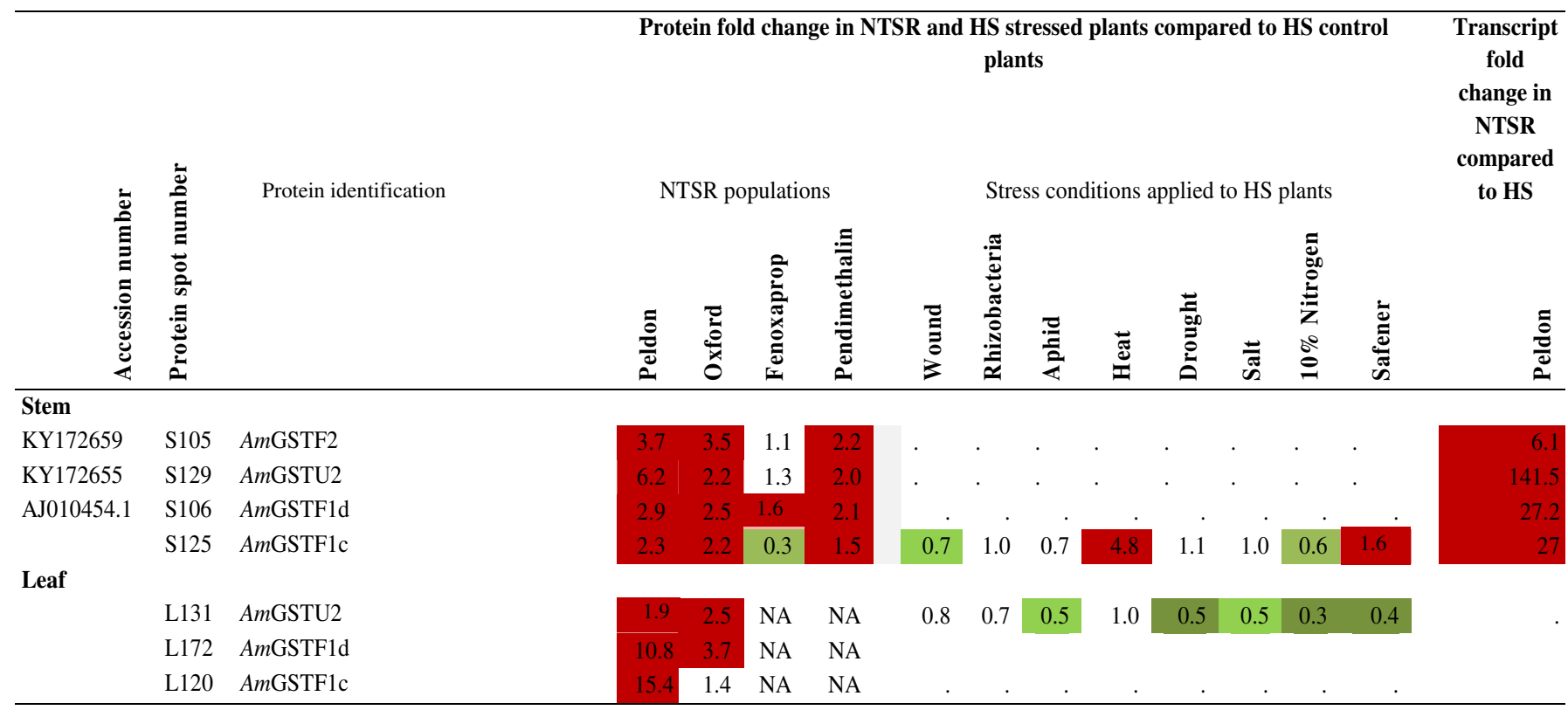

Figure 10. Relative abundance of GSTs in blackgrass determined in stem and leaf tissue in NTSR populations isolated from the field ('Peldon', 'Oxford') and from forced selection with the herbicides pendimethalin, or fenoxaprop. Significant differences in fold-abundance $(p<0.05$, fold change $>1.5)$ were relative to equivalent herbicide sensitive (HS) plants. The difference in transcript abundances (NTSR vs. HS) are presented in different color codes with red representing enhanced and green representing suppressed transcript abundance. (NA = not analyzed).

turnover. Similar discrepancies in transcriptome and proteome expression patterns have been reported for GSTs in other plants responding to stress conditions and may reflect the manner in which these genes are evolving through the process of gene duplication (Dixon and Edwards 2010). In this regard, it is interesting that AmGSTU2 is orthologous to TaGSTU4, an enzyme that displays a range of detoxifying activities following minor changes in its coding sequence (Govindarajan et al. 2015). We conclude that while AmGSTF1 and its variants have the potential to evolve new signaling-related roles in NTSR, the AmGSTU2 isoforms could rapidly develop new herbicidedetoxifying activities. Further characterization of the functional diversity of these GSTs in the future may help explain the multiple herbicide-resistant phenotypes observed in different NTSR A. myosuroides populations.

\section{Metabolic Herbicide Resistance in Lolium spp.}

Resistance to small grain-selective acetolactate synthase (ALS)and acetyl CoA carboxylase (ACCase)-inhibiting herbicides is common in Lolium spp. (L. rigidum, L. perenne) in the United States, Europe, and especially Australia (Boutsalis et al. 2012; Broster and Pratley 2006; Heap 2018; Owen et al. 2014). Both target-site resistance (TSR) and NTSR mechanisms have evolved, and these often co-occur within individuals and within populations (Han et al. 2016; Yu and Powles 2014). Metabolism-based resistance in L. rigidum from Australia has evolved to wheatselective ACCase and ALS herbicides with a mosaic of different cross-resistance and inheritance patterns indicative of multiple resistance genes and pathways (reviewed in $\mathrm{Yu}$ and Powles 2014). Resistance to the ACCase inhibitor diclofop has been experimentally evolved from initially susceptible individuals (Manalil et al. 2011; Neve and Powles 2005), and the high level of resistance achieved is due to enhanced diclofop metabolism (Yu et al. 2013). Inheritance of the resistance is polygenic (Busi et al. 2013),
Table 3. Activities of purified recombinant glutathione S-transferase (rGST) enzymes from Alopecurus myusuroides in conjugating 1-chloro-2,4-dinitrobenzene (CDNB) and herbicide substrates and as a glutathione peroxidase acting on $t$-butyl hydroperoxide.

\begin{tabular}{lcc}
\hline & \multicolumn{2}{c}{ Specific activity (nkat $\mathrm{mg}^{-1} \mathrm{rGST}$ ) } \\
\cline { 2 - 3 } Substrate & AmGSTF1c & AmGSTU2a \\
\hline CDNB & $670 \pm 36$ & $608 \pm 56$ \\
\hline Metolachlor & $16.9 \pm 4.9$ & $10.4 \pm 1.3$ \\
\hline Fenoxaprop-ethyl & $0.0 \pm 0.0$ & $0.6 \pm 0.1$ \\
\hline$t$-Butyl hydroperoxide & $50.04 \pm 13.3$ & $0 \pm 0$ \\
\hline
\end{tabular}

consistent with the hypothesis that multiple genes may contribute to metabolic resistance. Interestingly, diclofop-susceptible populations were selected for even greater sensitivity (Manalil et al. 2012), and protection against diclofop due to enhanced metabolism could be induced in susceptible individuals by 2,4-D application (Han et al. 2013). Metabolic resistance to pyroxasulfone was experimentally evolved from a population that already had metabolic resistance to ACCase, ALS, and mitosis inhibitors (Busi et al. 2012), but no pyroxasulfone resistance evolved following repeated selection on a susceptible population. The experimentally evolved pyroxasulfone resistance appeared to be controlled by a single gene (Busi et al. 2014), and the population was also cross-resistant to prosulfocarb and triallate, with a subsequent selection using prosulfocarb resulting in higher prosulfocarb resistance (Busi and Powles 2013, 2016). Pyroxasulfone resistance in the experimentally evolved population is due to glutathione conjugation and subsequent metabolic steps on pyroxasulfone, with the first step likely mediated by GSTs (Busi et al. 2018). Some insecticides can reverse metabolic resistance in L. rigidum by inhibiting CYPs, including malathion for chlorsulfuron resistance (Christopher et al. 1994) and amitrole for diclofop 
resistance (Preston and Powles 1998). Phorate reverses chlorsulfuron, pyroxasulfone, and trifluralin resistance, but antagonizes the efficacy of prosulfocarb and triallate that normally are effective on L. rigidum (Busi et al. 2017). Enhanced metabolism for herbicide resistance is still not completely understood and can complicate L. rigidum management due to unpredictable crossresistance patterns (Preston 2004).

Metabolic resistance in L. rigidum has been associated with increased expression of genes with roles in metabolism, such as CYPs, GSTs, and GTs (Duhoux et al. 2015; Gaines et al. 2014). Although not yet reported, metabolic herbicide resistance could also be due to nonsynonymous mutations in metabolism genes, resulting in faster herbicide metabolism due to changes in substrate affinity. An RNA-seq transcriptome analysis was used to identify genes conferring enhanced metabolic resistance in a L. rigidum population experimentally evolved for diclofop resistance (Gaines et al. 2014). Candidate transcripts identified as overexpressed in resistant plants cosegregated with the resistance phenotype in an $\mathrm{F}_{2}$ population, including CYPs, GSTs, and GTs. A set of four transcripts (two CYPs, one nitrogen monooxygenase, and one GT), initially identified from the experimentally evolved diclofopresistant population, were upregulated in individuals from nine unrelated $L$. rigidum populations with metabolic resistance (Gaines et al. 2014). A cluster analysis demonstrated the potential of these four transcriptional markers in resistance diagnostics when multiple individuals were sampled from different populations, as herbicide-susceptible individuals clustered together and populations containing metabolic resistant individuals could be classified as resistant (Figure 11). Candidate resistance genes from this $L$. rigidum population are being functionally validated, and additional populations from Australia with different metabolic resistance patterns are being evaluated with transcriptomics for candidate resistance genes. An RNA-seq analysis of ALS-resistant L. rigidum from France identified a set of 19 transcripts associated with metabolic ALS resistance (Duhoux et al. 2015). These 19 transcriptional markers provided diagnostic prediction of herbicide resistance in French Lolium spp. populations (Duhoux et al. 2017a). The functional role of transcriptional marker genes in Lolium spp. has yet to be evaluated.

A major question for metabolic herbicide resistance is that some genes associated with resistance across multiple populations through RNA-seq studies may not have a functional role in resistance, that is, they may not be the genes responsible for direct metabolic modifications to herbicides. These genes could be genetically linked to the major resistance gene(s), they could be co-regulated by a common transcription factor, or they could be co-regulated through chromatin structural changes. These genes may have other functions in resistance besides direct herbicide metabolism, or they could have no functional role in resistance at all. Improved basic knowledge about the molecular genetic basis of metabolic resistance and linked or co-regulated genes is necessary to develop metabolic resistance diagnostics based on molecular markers.

\section{Mechanisms of Multiple Resistance in Echinochloa phyllopogon}

Herbicide resistance in E. phyllopogon has been reported in populations in France, Greece, Brazil, South Korea, and the United States (Délye et al. 2015; Kaloumenos et al. 2012; Matzenbacher et al. 2014; Song et al. 2017). The populations in France, Greece, and Brazil are resistant to ALS inhibitors due mainly to TSR mechanisms, although additional NTSR mechanisms were not excluded. Conversely, populations in South Korea and the United States are known to have NTSR mechanisms and exhibit resistance to several herbicides with different modes of action. Here, the study on the resistance mechanism of E. phyllopogon found in the United States is reviewed.

\section{Multiple Herbicide-Resistant Echinochloa phyllopogon}

The Sacramento Valley of California is one of the largest rice production areas in the United States. Since the introduction of molinate and thiobencarb in the 1960s and 1980s, respectively, the two thiocarbamate herbicides were preferentially used for Echinochloa control (Fischer et al. 2000a). In 1994, another option from Group 1, fenoxaprop-ethyl, was introduced for POST control of Echinochloa spp. (Williams 2000). Soon after, the failure in control of E. phyllopogon by herbicides that previously controlled it was reported by farmers (Fischer et al. 2000a). Greenhouse experiments conducted on the plants collected from fields in 1997 revealed that the plants exhibited resistance to fenoxaprop-ethyl,

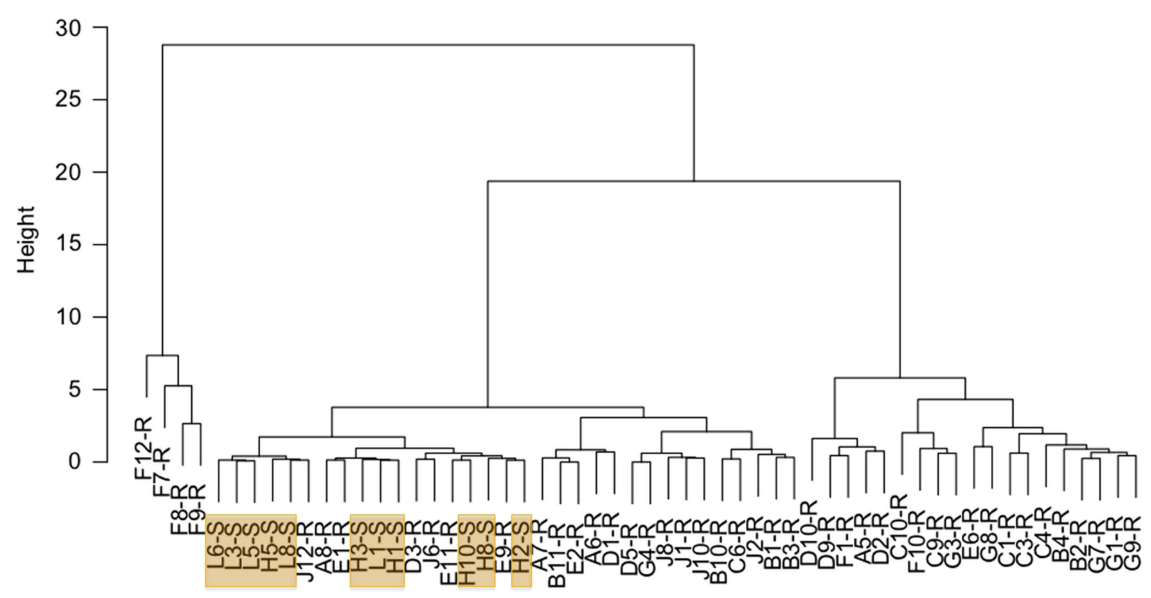

Figure 11. Transcriptional markers for metabolic herbicide resistance can be used to diagnose populations as resistant or susceptible (adapted from Gaines et al. 2014). A cluster analysis of expression levels of four transcriptional markers (increased expression of two cytochrome P450s, one nitrogen monooxygenase, and one glucosyl transferase) differentiates herbicide-susceptible individuals (samples ending in S, highlighted in boxes) from populations containing metabolic resistant individuals, which could be classified as resistant based on their clustering. The results highlight the importance of sampling multiple individuals for transcriptional marker diagnostics. 
molinate, thiobencarb, and bispyribac-sodium, a herbicide that was not released yet (Fischer et al. 2000a; Osuna et al. 2002). Later, the research group revealed that the resistant E. phyllopogon also exhibited resistance to cyhalofop-butyl, penoxsulam, bensulfuron-methyl, quinclorac, and clomazone, most of which had not been in use by 1997 .

\section{Mechanism of Resistance to ALS Inhibitors}

\section{Metabolism-based Resistance}

Multiple herbicide-resistant E. phyllopogon is resistant to three ALS-inhibiting herbicides, bispyribac-sodium, penoxsulam, and bensulfuron-methyl, each belonging to a different chemical family. There are several reports of resistance factors that were estimated from different experiments in different cultivation conditions or with different lines (Fischer et al. 2000a, 2000b; Osuna et al. 2002; Yasuor et al. 2009). When compared under the same experimental conditions, the resistance factor for line 511, which was the line used for molecular analysis, was about 1,100-fold for bensulfuronmethyl, 6.2-fold for penoxsulam (Iwakami et al. 2014a), and 1.8fold for bispyribac-sodium (unpublished data).

No difference was observed in the sensitivity of the target site to these herbicides in vitro (Fischer et al. 2000b; Osuna et al. 2002; Yasuor et al. 2009). In accordance with the enzyme assay, the nucleotide sequences of the two copies of ALS genes were identical between resistant and sensitive plants (Iwakami et al. 2012). These studies confirm that ALS resistance is not caused by TSR. Studies on metabolism were mainly conducted on penoxsulam using $\left[{ }^{14} \mathrm{C}\right]$ penoxsulam. Resistant plants metabolized penoxsulam into polar metabolites 2.8 times faster than sensitive plants (Yasuor et al. 2009). A CYP inhibitor, malathion, inhibited the metabolism of penoxsulam. Similarly, faster metabolism in resistant plants was confirmed in bensulfuron-methyl. The resistant plants metabolized bensulfuron-methyl into a demethylated form (Iwakami et al. 2014a), which is known to lose ALS-inhibiting activity (Takeda et al. 1986). Although metabolism was not tested for bispyribacsodium, Fischer et al. (2000b) revealed application of CYP inhibitors partially reversed bispyribac-sodium resistance.

\section{Isolation of CYP81A CYP Genes from Echinochloa phyllopogon} CYPs comprise a superfamily with hundreds of genes in plant genomes (Nelson et al. 2004). A recent study by Guo et al. (2017) revealed that a hexaploid close relative of E. phyllpogon, barnyardgrass [Echinochloa crus-galli (L.) P. Beauv.], possesses as many as 917 CYP genes in its genome, suggesting the number is also large in tetraploid E. phyllopogon. The very large number of genes has made the analysis of genes difficult, especially in weed species with no reference genome sequence. Although a CYP gene involved in rice tolerance to some herbicides has been identified (Pan et al. 2006), no CYP genes involved in herbicide resistance in weeds were identified before the study conducted in E. phyllopogon. The CYP gene belongs to CYP81A subfamily (CYP81A6) and is involved in tolerance to various ALS-inhibiting herbicides, including bensulfuron-methyl.

Attempts to isolate CYP genes from E. phyllopogon were started by nested degenerate PCR using the very few conserved regions of $\mathrm{P} 450$ genes, resulting in the isolation of 39 putative $\mathrm{P} 450$ genes, including seven CYP81A members (Iwakami et al. 2014b). Later, degenerate PCR was used to exclusively amplify CYP81A genes and succeeded in the isolation of five more CYP81A genes from resistant plants (Iwakami et al. 2014a). Among the 12 CYP81A genes, 3 are putative pseudogenes with indels that cause frameshifts.
Comparisons of full-length sequences between the resistant and sensitive plants found nonsynonymous substitutions in CYP81A21, CYP81A22, and CYP81A26.

\section{Characterization of CYP81A Genes}

Transcript levels of the nine CYP81A genes, except the three putative pseudogenes, were compared between resistant and sensitive plants (Iwakami et al. 2014a). Two genes, CYP81A12 and CYP81A21, were constitutively highly expressed in the resistant plants. The two genes share extremely high similarity and were estimated as homologues based on phylogenetic tree analysis. The estimation of homologous relationships was also supported by chromosome linkage analysis of the two genes (Iwakami et al., 2014a). The analysis was performed using nucleotide polymorphisms found in both genes between the resistant and sensitive plants. The results indicated there was no linkage between the two genes, which implies that the two genes are on different chromosomes, as expected from the homologous relationship. Overexpression was also observed in CYP81A22, although the overexpression was restricted to the roots of resistant plants.

Transgenic Arabidopsis expressing CYP81A12 or CYP81A21 exhibited significant resistance to bensulfuron-methyl (Iwakami et al. 2014a). The resistance factors of the highly expressing lines were more than 1,000-fold, suggesting the CYPs metabolize bensulfuron-methyl very effectively. An in vivo bensulfuronmethyl metabolism experiment using yeast revealed that the two CYPs demethylate bensulfuron-methyl. The results explain the higher amount of demethylated form of bensulfuron-methyl in the resistant E. phyllopogon. Association of bensulfuron-methyl resistance and the higher expressions of the two genes were investigated in the $\mathrm{F}_{6}$ generation of the progenies of the resistant and sensitive E. phyllopogon. The experiment showed that bensulfuron-methyl resistance was associated with higher expression in all the $\mathrm{F}_{6}$ lines tested. In contrast to CYP81A12 and CYP81A21, CYP81A22 did not confer bensulfuron-methyl resistance in Arabidopsis. Higher expression of CYP81A22 observed in the resistant parent did not cosegregate with resistance in the study of the $\mathrm{F}_{6}$ generation. Genotyping of $\mathrm{F}_{6}$ lines also revealed that amino acid substitutions found in CYP81A21, CYP81A22, and CYP81A26 were not associated with resistance. All the results strongly suggest that bensulfuron-methyl resistance in E. phyllopogon is caused by overexpression of CYP81A12 and CYP81A21.

The overexpression mechanism of the two genes was investigated from the aspects of the promoter sequence and copy number (Iwakami et al. 2014a). Polymorphisms between the resistant and sensitive lines were observed in the promoter sequences of the two genes, but neither of them cosegregated with resistance in the $F_{6}$ lines. Also, no difference was detected in the copy number by Southern blot analysis. Considering the two genes are on different chromosomes and the resistance is under the control of a single gene (or locus), it is likely that a single trans-element simultaneously regulates the expression of both genes.

\section{Mechanism of Penoxsulam Resistance}

It is reasonable to infer that the same mechanism that controls bensulfuron-methyl resistance also controls the penoxsulam resistance, based on the metabolism and inheritance studies presented. As expected, bensulfuron-methyl and penoxsulam resistance did not segregate in $\mathrm{F}_{6}$ lines (Iwakami et al. 2014a). Arabidopsis lines transformed with CYP81A12 or CYP81A21 exhibited significant resistance to penoxsulam. Interestingly, the 
Arabidopsis that exhibited $>1,000$-fold resistance to bensulfuronmethyl exhibited $\sim 10$-fold resistance to penoxsulam. These results suggest that CYP81A12 and CYP81A21 metabolize bensulfuron-methyl 100 -fold more efficiently than penoxsulam. This observation is consistent with the resistance levels to bensulfuron-methyl (1,100-fold) and penoxsulam (6.2-fold) in $E$. phyllopogon. In summary, the two CYP81A genes play a major role in not only bensulfuron-methyl, but also penoxsulam resistance.

\section{Bispyribac-Sodium Resistance Mechanism Is Not Clear}

In contrast to bensulfuron-methyl and penoxsulam, Arabidopsis expressing CYP81A12 or CYP81A21 did not show any significant resistance to bispyribac-sodium (unpublished data). The failure of endowing resistance to Arabidopsis does not necessarily indicate the genes are not involved in bispyribac-sodium resistance. RNAi knockdown rice of CYP81A6, an ALS-inhibitor tolerance gene in rice, has slightly higher sensitivity to bispyribac-sodium, although the difference is not very clear (Saika et al. 2014). Therefore, CYP81A CYPs may have functions of bispyribac-sodium metabolism. More detailed studies will be required to investigate the involvement of the $\mathrm{P} 450$ in resistance to bispyribac-sodium in E. phyllopogon.

\section{Mechanism of Resistance to ACCase Inhibitors}

Resistant E. phyllopogon plants exhibit resistance to AOPPs, fenoxaprop-ethyl and cyhalofop-butyl, with resistance factors of 10 and 19, respectively (Bakkali et al. 2007; Ruiz-Santaella et al. 2006). On the other hand, a cyclohexanedione ACCase inhibitor, profoxydim, can effectively control resistant plants (Ruiz-Santaella et al. 2003). ACCase sensitivity to fenoxaprop-ethyl did not differ between the resistant and sensitive lines. Nucleotide sequences of the carboxy transferase domain of ACCase, where all the resistance-conferring amino acid substitutions were found in other species, were compared between the resistant and sensitive E. phyllopogon. In accordance with the enzyme sensitivity, no resistance-conferring mutations were observed in the four copies of ACCase genes in E. phyllopogon. These results indicate that the ACCase resistance mechanism is non-target site based.

A metabolism study was performed for fenoxaprop-ethyl and cyhalofop-butyl. Rapid accumulation of GSH-conjugated metabolites in resistant plants strongly suggests that fenoxaprop-ethyl resistance is caused by enhanced activity of GST (Bakkali et al. 2007). Resistant plants accumulated more polar metabolites of cyhalofop-butyl than sensitive plants (Ruiz-Santaella et al., 2006). The results suggest that a mechanism in addition to overexpression of CYP81A12 and CYP81A21 endows multipleherbicide resistance in E. phyllopogon. The research to identify specific GSTs is ongoing.

\section{Mechanism of Resistance to Clomazone}

Echinochloa phyllopogon in rice fields had no prior exposure to clomazone. The resistance factor is not very high (2 times), so clomazone resistance eluded classification in the first screening (Fischer et al. 2000a; Yasuor et al. 2008). However, after the introduction of clomazone in the Sacramento Valley, control failures with clomazone were observed, leading to the findings of low-level resistance (Yasuor et al. 2008). A detailed study of clomazone resistance revealed that the resistant plants more rapidly metabolize clomazone into oxidative forms than sensitive plants, as described earlier: $5-\mathrm{OH}$ clomazone is converted to dihydroxy-clomazone and clomazone to hydroxymethylclomazone and 3 '-hydroxyclomazone (Yasuor et al. 2010). Therefore, it is possible that CYPs are involved in the reaction.

\section{Mechanism of Resistance to Quinclorac}

Enhanced metabolism has not been proposed as a weed resistance mechanism to quinclorac (Yasuor et al. 2012). Therefore, factors related to the mechanism of action of auxin herbicides were addressed.

The resistance factor to quinclorac is different between the methods of quinclorac application: foliar spray application, 6-fold; hydroponic root application, 17-fold (Yasuor et al. 2012). As with other auxin herbicides, quinclorac is known to induce high levels of ethylene production, which is highly related with plant sensitivity to quinclorac (Grossmann and Kwiatkowski 1993). This correlation is not fully understood, but it is thought to be caused by hydrogen cyanide ( $\mathrm{HCN})$ accumulation in plants as a by-product of ethylene production. Yasuor et al. (2012) compared the ethylene production of resistant and sensitive E. phyllopogon and found resistant plants produced significantly lower ethylene. Another interesting finding from their research was that resistant plants have higher activity of $\beta$-cyanoalanine synthase ( $\beta$-CAS), an enzyme that detoxifies $\mathrm{HCN}$. The authors concluded that quinclorac resistance in the resistant $E$. phyllopogon is caused by insensitivity along the ethylene production pathway and enhanced $\beta$-CAS activity.

\section{Future Work}

As reviewed here, extensive work on ALS-inhibitor resistance resulted in the identification of CYP involvement in resistance in $E$. phyllopogon. These genes may explain resistance to other herbicides such as clomazone, for which enhanced oxidation of clomazone was reported. On the other hand, the involvement of other herbicidemetabolizing genes, namely GSTs, are suggested in the case of fenoxaprop-ethyl resistance. Furthermore, even non-metabolism based resistance is suggested in quinclorac resistance. A hint to elucidate the apparently complicated mechanism(s) of multipleherbicide resistance may come from analyses of thiocarbamate (molinate and thiobencarb) resistance, which have not yet been investigated. Although findings of resistant populations in the Sacramento Valley occurred right after introduction of fenoxapropethyl, the driving force of resistance evolution may be continuous application of thiocarbamates for more than $20 \mathrm{yr}$. Therefore, elucidation of the resistance mechanism to thiocarbamates might provide an insight into how the evolution of multiple-herbicide resistance occurred in E. phyllopogon. A preliminary work suggested concerted upregulation of several gene families involved in herbicide metabolism (unpublished data), as has been reported in other metabolism-based resistant weeds (Duhoux et al. 2015, 2017a; Gaines et al. 2014; Gardin et al. 2015). Approaches such as genomics and transcriptomics will shed further light on the mystery of rapid evolution of resistance to multiple herbicides in E. phyllopogon.

Multiple Resistance and Metabolic Resistance Mechanisms in Junglerice (Echinochloa colona)

A junglerice [(Echinochloa colona (L.) Link] biotype MS1, collected from a rice field in Sunflower County, MI, was resistant to ALS-inhibiting imazethapyr and cross-resistant to other ALS inhibitors such as imazamox (3.3-fold), penoxsulam (9.4-fold), and bispyribac-sodium (7.2-fold) (Riar et. al. 2012). In 
preliminary experiments, the addition of malathion to penoxsulam and imazethapyr reduced shoot dry weight and/or increased mortality compared with the respective herbicides applied alone, indicating possible involvement of herbicide metabolism driven by CYPs as a mechanism of resistance. ALS enzyme assays or $A L S$ gene-sequencing analysis did not indicate a modified target site-based resistance in the MS1 biotype (Riar et. al. 2013). Lower levels of translocation of $\left[{ }^{14} \mathrm{C}\right]$ bispyribac and $\left[{ }^{14} \mathrm{C}\right]$ imazamox in the MS1 biotype compared with a susceptible biotype were recorded, perhaps indicating that metabolism is involved (Riar et. al. 2013). Additionally, the MS1 biotype was resistant to fenoxaprop- $P$-ethyl, an ACCase inhibitor (11-fold; but susceptible to sethoxydim and clethodim at field rates) (Wright et. al. 2016). Sequencing of ACCase of MS1 did not reveal the presence of any known resistance-conferring point mutations. An enzyme assay confirmed that the ACCase in the MSI biotype was herbicide sensitive. Further investigations with two CYP inhibitors, malathion and piperonyl butoxide, and a GST inhibitor, 4-chloro-7-nitrobenzofurazan (CNBF), did not indicate involvement of any metabolic enzymes inhibited by these compounds (Wright et al. 2016).

No reference genome is available for E. colona. RNA-seq analysis of changes in gene expression in the MS1 and a susceptible biotype before and after imazamox treatment was conducted to generate a reference leaf transcriptome (Wright et al. 2017). Differentially expressed transcripts between resistant MS1 and susceptible plants included transcription factors, proteinmodifying enzymes, and enzymes involved in metabolism and signaling, which are involved in abiotic stress response in other plants. These results suggest that imazamox exposure induced a stress response. A time-course study examining a subset of transcripts showed that expression peaked within 4 to $12 \mathrm{~h}$ and then returned to untreated levels within $48 \mathrm{~h}$ of exposure. Two additional biotypes showed a similar change in gene expression at $4 \mathrm{~h}$ after herbicide exposure compared with the resistant and sensitive biotypes. Thus, within $48 \mathrm{~h}$, E. colona mounted a stress response to imazamox exposure (Wright et al. 2017).

The MSI biotype was resistant to propanil and quinclorac as well (Wright et al. 2018). Differential gene expression analysis of resistant and sensitive plants revealed that 170 transcripts were upregulated in resistant plants relative to sensitive plants, and 160 transcripts were upregulated in sensitive plants. In addition, 507 transcripts were only expressed in resistant plants, and 562 only in sensitive plants. A subset of these transcripts was investigated further using quantitative PCR (qPCR) to compare gene expression in resistant plants with expression in additional sensitive biotypes. The qPCR analysis identified two transcripts, a kinase and a GST that were significantly upregulated in resistant plants compared with the sensitive plants. A third transcript, encoding an F-box protein, was downregulated in the resistant plants relative to the sensitive plants. As no CYPs were differentially expressed between the resistant and sensitive plants, a singlenucleotide polymorphism analysis was performed, revealing several nonsynonymous point mutations of interest. These candidate genes will require further study to elucidate the resistance mechanisms present in the resistant biotype (Wright et al. 2018).

Metabolism-based Multiple Resistance in Amaranthus palmeri

As a result of extensive and intensive selection of PRE and/or POST use of most commonly used herbicides in cropping systems, A. palmeri has evolved resistance to multiple modes of action, for example, microtubule, EPSPS, ALS, PSII, HPPD, and, more recently, protoporphyrinogen oxidase (PPO) inhibitors (Heap 2018). Besides herbicide selection, other factors such as biological characteristics of weed species, genetic factors, characteristics of herbicides, and agronomic practices also play an important role in the evolution and spread of herbicide resistance in weed species (Powles and Yu 2010). Amaranthus palmeri characteristics such as high fecundity, germination percentage, wide window of emergence, seed dispersal, and short longevity facilitate the evolution of resistance in response to herbicide selection. Recent advances in agronomic practices have increased adoption of no-till or reduced-tillage practices in crop production to prevent soil erosion and conserve moisture (Kihara et al. 2012). Consequently, the use of herbicides for weed management became indispensable in crop production in many parts of the world, creating greater herbicide selection.

\section{Evolution of Multiple Herbicide Resistance in Amaranthus palmeri in Kansas}

Amaranthus palmeri populations resistant to four mechanism of actions of herbicides-PSII, ALS, EPSPS, and HPPD inhibitorshave been reported in Kansas (Heap 2018). Several populations of A. palmeri with resistance to at least two of these herbicide modes of action are common in Kansas. However, a single population of A. palmeri (KSR) in central Kansas (Stafford County) with resistance to PSII and HPPD inhibitors was first confirmed in 2012 (Thompson 2012) in a field where there was no previous history of applications of HPPD inhibitors but a long history of PSII- and ALS-inhibiting herbicides. This population was originally found resistant to Huskie ${ }^{\circledR}$, a premix of pyrasulfotole (HPPD inhibitor) and bromoxynil (PSII inhibitor) in the field. Later, resistance to atrazine (Nakka et al. 2017a; Thompson et al. 2012), chlorsulfuron (Nakka et al. 2017b), and several HPPD inhibitors (e.g., mesotrione, tembotrione, and topramezone) (Nakka et al. 2017c; Thompson et al. 2012) was confirmed and characterized in this population. Investigation of the mechanism of resistance to atrazine, chlorsulfuron, and mesotrione in this population enabled addressing why this population was predisposed to evolve resistance to HPPD inhibitors even though there was no selection of HPPD inhibitors.

\section{Mechanism of Atrazine Resistance in KSR Amaranthus palmeri}

Several mutations in the $p s b A$ gene, which codes for D1 protein, the target site of PSII inhibitors (triazine, triazinone, uracil, nitrile, etc.), resulted in the evolution of resistance or cross-resistance to different classes of PSII inhibitors (Arntz et al. 2000; Gronwald 1994; Oettmeier 1999). Furthermore, such resistance to atrazine has been found to be associated with fitness costs as well (Conard and Radosevich 1979). However, enhanced metabolism of atrazine or simazine via GST activity has also been reported in many triazine-resistant weed species (Burnet et al. 1993; Cummins et al. 1999; Gray et al. 1996; Ma et al. 2013). Similarly, crops such as corn or sorghum are also naturally tolerant to triazines due to rapid metabolism of these herbicides mediated by GST activity.

A high level of resistance to atrazine was confirmed in KSR $A$. palmeri exhibiting up to 200 -fold resistance relative to a known susceptible population (Nakka et al. 2017a). No known mutation in the $p s b A$ gene conferring the most common substitution (Ser- 
264-Gly) was found in KSR A. palmeri (Nakka et al. 2017a). Also, the resistance trait is not maternally inherited, but rather is transmitted by a nuclear gene in this population (Nakka et al. 2017a). On the other hand, the KSR A. palmeri rapidly conjugated $\left[\mathrm{U}^{-14} \mathrm{C}\right]$ atrazine, possibly via GSH mediated by GST activity, within $4 \mathrm{~h}$ after treatment (Nakka et al. 2017a).

\section{Mechanism of Chlorsulfuron Resistance in KSR Amaranthus palmeri}

The ALS enzyme, which is the target site of ALS inhibitors, catalyzes an important step in the biosynthesis of the branched-chain amino acids valine, leucine, and isoleucine in plants and microorganisms (Dailey and Cronan 1986; Shaner 1991). SU herbicides such as chlorsulfuron are active on several weed species, including A. palmeri. However, A. palmeri resistance to ALS inhibitors is widespread across many states in the United States, including Kansas (Heap 2018). ALS inhibitor-resistant A. palmeri was first documented in Kansas in 1993 (Horak and Peterson 1995).

A high level of resistance to ALS inhibitors due to several point mutations in the ALS gene has been reported in many weed species (Foes et al. 1999; Guttieri et al. 1995; Patzoldt and Tranel 2007; Shaner 1991; Tranel et al. 2016; Varanasi et al. 2015). Nonetheless, enhanced metabolism of ALS inhibitors contributing to resistance has also been found in a number of weeds, for example, L. rigidum (Christopher et al. 1991; Cotterman and Saari 1992), wild mustard (Sinapsis arvensis L.) (Veldhuis et al. 2000), and A. tuberculatus (Guo et al. 2015). Increased activity of CYPs in the metabolism of this group of herbicides has been reported (Brown 1990; Christopher et al. 1994).

The KSR A. palmeri exhibited $>275$ times more resistance to chlorsulfuron relative to a known susceptible population (Nakka et al. 2017b). Such a high level of resistance to ALS inhibitors has also been reported in other Amaranthus species, including redroot pigweed (Amaranthus retroflexus L.) (Scarabel et al. 2007), Powell amaranth (Amaranthus powellii S. Watson) (Ferguson et al. 2001), prostrate pigweed (Amaranthus blitoides S. Watson) (Sibony et al. 2001; Sibony and Rubin 2003), smooth pigweed (Amaranthus hybridus L.) (Whaley et al. 2006, 2007), and common waterhemp (Amaranthus rudis J. D. Sauer) (Patzoldt and Tranel 2007).

Upon sequencing of an $\sim 2-\mathrm{kb}$ length of the $A L S$ gene covering all known mutations at eight codon positions in KSR A. palmeri, only $30 \%$ of plants showed the single-nucleotide polymorphism, resulting in an amino acid substitution of proline (CCC) to serine (TCC) at position 197 of the ALS gene. The remaining $70 \%$ of KSR plants did not show any mutations (Nakka et al. 2017b). Further, whole-plant response of KSR A. palmeri treated with a combination of chlorsulfuron and malathion (an organophosphate insecticide, known to inhibit the activity of CYPs) showed reduction in biomass accumulation when compared with plants that were treated with either malathion or chlorsulfuron alone or nontreated plants (Nakka et al. 2017b), indicating the synergistic effect of malathion on chlorsulfuron. These data suggest that KSR A. palmeri exhibits two different mechanisms of ALS-inhibitor resistance: (1) detoxification of chlorsulfuron, possibly as a result of CYP activity; and (2) a point mutation (Pro-197-Ser) in the $A L S$ gene. However, metabolism-based resistance appears to exist predominantly in KSR A. palmeri (Nakka et al. 2017b). The KSR A. palmeri population is a prime example of a weed population exhibiting coexistence of both TSR and metabolism-based resistance to ALS inhibitors.
Mechanism of Mesotrione Resistance in KSR Amaranthus palmeri

Herbicides such as mesotrione that inhibit HPPD enzyme are widely used to control a broad spectrum of weeds in agriculture. Mesotrione inhibits carotenoid biosynthesis, resulting in pigment degradation and, eventually, plant death. However, crops such as corn can rapidly metabolize these herbicides via ring hydroxylation mediated by cytochrome P450 monooxygenase(s) combined with reduced uptake (Mitchell et al. 2001). To date, only two weed species, $A$. rudis and $A$. palmeri, have evolved resistance to HPPD inhibitors (Heap 2018). HPPD inhibitor-resistant $A$. rudis was first reported in Illinois in 2009 (Hausman et al. 2011). This biotype of $A$. rudis was also found to be resistant to atrazine. Detoxification of mesotrione, possibly mediated by CYP and atrazine via GST-mediated conjugation, has been attributed to mesotrione and atrazine resistance, respectively, in this A. rudis population (Ma et al. 2013).

The HPPD-inhibitor resistance in KSR A. palmeri was documented in Kansas in 2012 (Thompson et al. 2012), and later in Nebraska in a cornfield that had a history of continuous use of HPPD inhibitors (Sandell et al. 2012). As mentioned earlier, the field where KSR A. palmeri was found had no previous history of use of HPPD inhibitors. The KSR A. palmeri was up to 18 times more resistant to mesotrione compared with a known sensitive population (Nakka et al. 2017c). There was no difference in uptake or translocation of mesotrione or its metabolites between KSR and a known susceptible A. palmeri biotype (Nakka et al. 2017c). However, similar to mesotrione-resistant A. rudis, KSR A. palmeri also rapidly metabolized $\left[{ }^{14} \mathrm{C}\right]$ mesotrione. At 4 and $24 \mathrm{~h}$ after treatment about $50 \%$ and $90 \%$ of parent $\left[{ }^{14} \mathrm{C}\right]$ mesotrione was metabolized, respectively, in KSR plants (Nakka et al. 2017c). Furthermore, the KSR plants were found to detoxify $50 \%$ of mesotrione in a shorter time compared with corn or A. rudis (Ma et al. 2013; Nakka et al. 2017c).

To assess the possibility of coexistence of TSR and NTSR to HPPD inhibitors in KSR A. palmeri, as was observed for ALS inhibitors, the HPPD gene was sequenced and amplified for KSR and a susceptible $A$. palmeri. However, no mutations or amplification of the HPPD gene that can confer resistance to mesotrione was found (Nakka et al. 2017c). Interestingly, the KSR plants exhibited increased constitutive expression of HPPD transcript and protein (Nakka et al. 2017c). The mesotrioneresistant KSR plants showed at least 8- to 12-fold increase in HPPD mRNA levels (normalized against $\beta$-tubulin and carbamoyl-phosphate synthase) relative to susceptible plants. Also, the HPPD protein expression correlated with the transcript expression (Nakka et al. 2017c). The upregulation of HPPD transcript in KSR plants could have occurred via changes in the cis- or trans-acting elements or alterations in the promoter region of the HPPD gene. Overall, the mesotrione resistance in KSR A. palmeri is conferred predominantly because of rapid detoxification of mesotrione, although increased HPPD gene and protein expression also plays a role in the resistance mechanism.

\section{The Predominance of Metabolism-based Multiple-Herbicide Resistance in KSR}

The KSR A. palmeri clearly showed the predominance of metabolism-based resistance to multiple herbicides (Figure 12). The exact chronology of the evolution of resistance to PSII or ALS inhibitors, in this population is unknown. However, in Kansas, 
resistance to ALS inhibitors in A. palmeri was documented before resistance to PSII inhibitors (Heap 2018), but the resistance to HPPD inhibitors evolved more recently in this population (Thompson 2012). It is believed that resistance to ALS inhibitors may have evolved before resistance to PSII inhibitors in the KSR A. palmeri population as well. Regardless, the predominance of metabolism-based resistance to ALS and PSII inhibitors mediated by CYP or GST activity during the phase I and II detoxification process suggests the presence of increased activity of these enzymes, which potentially predisposed this population to detoxify other xenobiotics such as HPPD inhibitors, even though no selection pressure from this herbicide was imposed on this population. The role of specific genes of the CYP enzyme family in detoxification of chlorsulfuron or GSTs in atrazine metabolism is yet to be uncovered. Thus, the prevalence of metabolism-based resistance to ALS and PSII inhibitors may have predisposed this population to evolve resistance to HPPD inhibitors. Current research suggests that the metabolism-based herbicide resistance can be a serious threat to weed management, especially in weeds such as A. palmeri, which is one of the top-ranked economically important weeds across the United States.

\section{Biochemical Mechanisms Conferring Multiple Herbicide Resistance in Amaranthus tuberculatus}

Amaranthus tuberculatus is a problematic, summer annual broadleaf weed species severely affecting maize, soybean, sorghum, and cotton production in the United States (Hager et al. 2002; Heap 2018; Steckel and Sprague 2004). The $\mathrm{C}_{4}$ carbonfixation pathway and prolonged emergence period are two factors that allow A. tuberculatus to compete with crops in the field, especially under hot and dry weather conditions (Steckel 2007). No new herbicide modes of action have been commercialized in the past three decades (Duke 2012). Genes conferring resistance are easily spread throughout natural A. tuberculatus populations by pollen flow due to the obligate-outcrossing nature of A. tuberculatus, which makes effective herbicide options for management of this weed even more limited (Costea et al. 2005; Steckel 2007).

An A. tuberculatus population (named MCR) from central Illinois was the first reported natural weed population to evolve resistance to HPPD-inhibiting herbicides (Hausman et al. 2011), chronologically representing the fifth herbicide site-of-action group for resistance in A. tuberculatus (Heap 2018). A different A. tuberculatus population from Nebraska (named NEB) also demonstrated resistance to HPPD-inhibiting herbicides (Kaundun et al. 2017), and another A. tuberculatus population from Nebraska exhibited resistance to the synthetic auxin herbicide 2,4-D (Figueiredo et al. 2018). In each of these cases, rapid herbicide metabolism contributed to or conferred resistance in the population, as described in the following sections.

In addition to HPPD-inhibitor resistance in MCR, this population is resistant to $s$-triazines, ALS-inhibiting herbicides, and the foliar-applied PPO-inhibiting herbicide carfentrazone-ethyl (Ma et al. 2015; unpublished data). Neither altered target sites (HPPD for mesotrione or $p s b A$ encoding the D1 protein in PSII for $s$-triazines) nor increased uptake of mesotrione or atrazine was detected in the MCR population. Biochemical studies using excised leaves and whole plants derived from vegetative clones demonstrated that elevated rates of metabolism, through distinct detoxification pathways, contribute to herbicide resistance in MCR (Ma et al. 2013). These metabolic pathways include: (1) oxidative metabolism (presumably via CYPs) for two HPPD-inhibiting herbicides, mesotrione (Ma et al. 2013) and topramezone (Ma et al. 2018), as well as the ALS-inhibiting herbicide primisulfuron-methyl (Guo et al. 2015; Ma et al. 2015); and (2) GSH conjugation catalyzed by GSTs for atrazine (Evans et al. 2017; Ma et al. 2013; $\mathrm{Ma}$ et al. 2016). The use of an excised leaf assay and vegetatively cloned plants ensured that the herbicide-metabolism assay was independent of whole-plant translocation patterns and that identical $A$. tuberculatus genotypes were analyzed within a biochemical time-course analysis (Ma et al. 2015). The CYP inhibitors malathion and tetcyclacis decreased mesotrione metabolism and further reduced the biomass of MCR plants when applied with mesotrione ( $\mathrm{Ma}$ et al. 2013). Additionally, malathion resulted in a greater injury to MCR from ALSinhibiting herbicides, including primisulfuron, cloransulam, sulfometuron, pyrithiobac, and imazethapyr (Guo et al. 2015). Treatment with the GST inhibitor CNBF followed by an atrazine PRE or POST application significantly enhanced biomass reduction in another atrazine-resistant $A$. tuberculatus population from central Illinois (ACR) compared with the atrazineonly treatment ( $\mathrm{Ma}$ et al. 2016). These increased herbicide activities when applied with metabolic inhibitors to resistant $A$. tuberculatus further support metabolism-based resistance mechanisms to multiple herbicides in A. tuberculatus. Similarly, rapid mesotrione metabolism via 4-hydroxylation of the dione ring was detected in the NEB population compared with a sensitive population (Kaundun et al. 2017). Rapid metabolism of 2,4-D contributes to resistance in another A. tuberculatus population from Nebraska, which is also potentially mediated by CYP activity (Figueiredo et al. 2018).

Genetic and Molecular Basis of Multiple-Herbicide Resistance in A. tuberculatus

Metabolism-based herbicide resistance can confer unpredictable and complicated cross- or multiple resistance to herbicides with the same or different sites of action, which could be controlled by quantitative trait(s) (Délye 2013). A genetic study using $F_{2}$ segregating lines of multiple herbicide-resistant (MCR) and sensitive $A$. tuberculatus populations demonstrated that atrazine resistance in the MCR population is conferred by a single, incompletely dominant nuclear gene, whereas the inheritance of mesotrione resistance in the MCR population is more complex and appears to be a multigenic trait (Huffman et al. 2015). Following up on the atrazine resistance trait in the MCR and ACR populations, traditional protein purification and proteomic methods tested the hypothesis that enhanced metabolic detoxification of atrazine occurs by a distinct GST isozyme (Evans et al. 2017), which ultimately confers atrazine resistance in the MCR population. Several GST proteins were identified by liquid chromatography-mass spectrometry in affinity-purified fractions from $A$. tuberculatus using peptide sequence similarity with GSTs from Arabidopsis or other dicots. Elevated, constitutively expressed transcript levels of one phi-class GST (named AtuGSTF2) strongly correlated with atrazine resistance in A. tuberculatus (MCR and ACR populations) and an $\mathrm{F}_{2}$ population that segregates for metabolic atrazine resistance (Huffman et al. 2015). This correlation indicates that AtuGSTF2 is the predominant GST protein that confers atrazine resistance in A. tuberculatus (Evans et al. 2017), although additional 


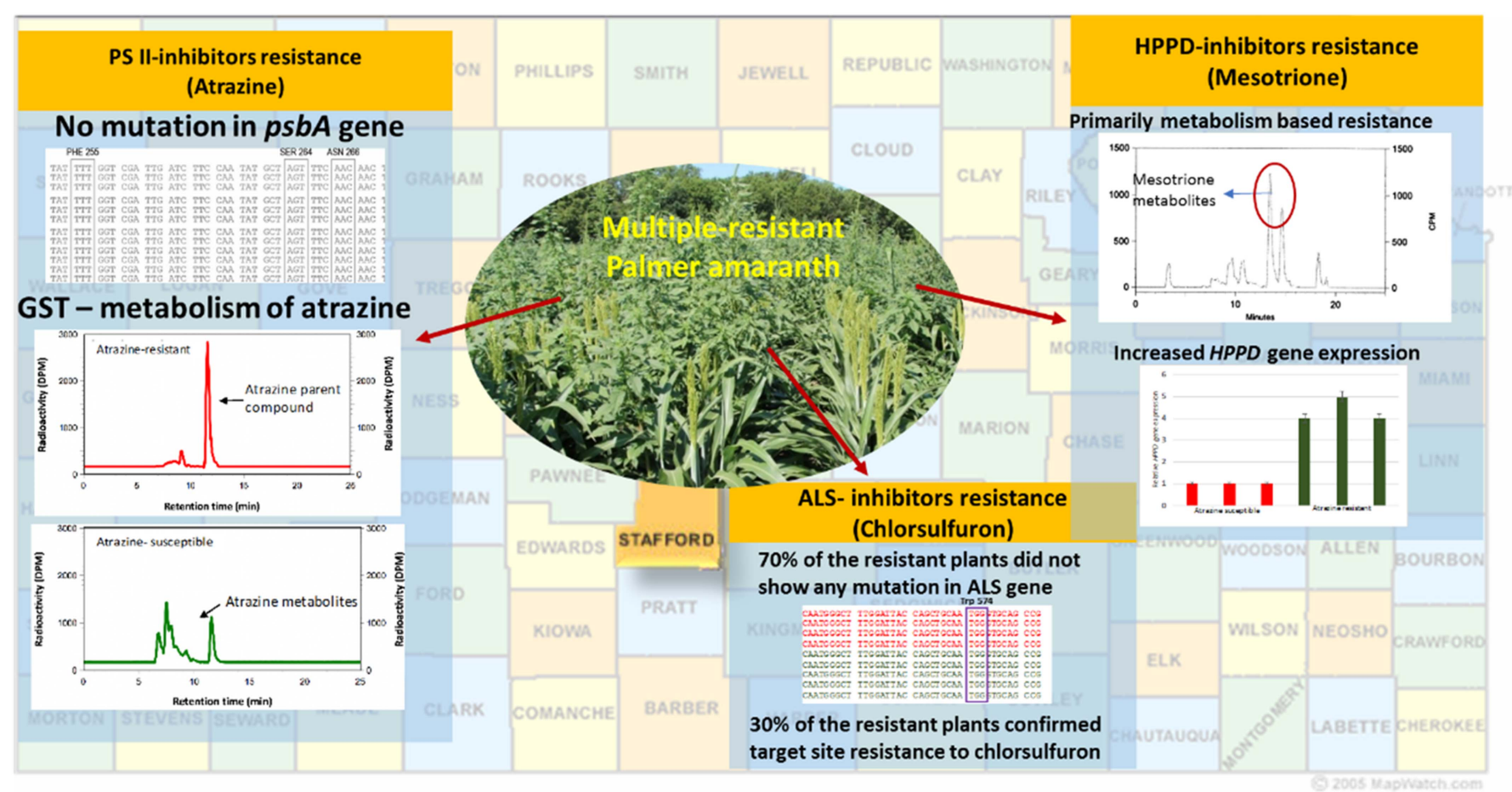

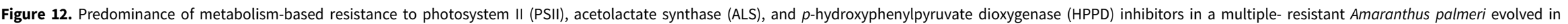
Stafford County, KS. 
<smiles>CS(=O)(=O)c1ccc(C(=O)C2C(=O)CCCC2=O)c(Cl)c1COCC(F)(F)F</smiles>

B<smiles>CS(=O)(=O)c1ccc(C(=O)C2C(=O)CCCC2=O)c([N+](=O)[O-])c1</smiles>

C<smiles>Cc1c(C(=O)c2c[nH]n(C)c2=O)ccc(S(C)(=O)=O)c1C1=NOCC1</smiles>

Figure 13. Chemical structures of (A) tembotrione, (B) mesotrione, and (C) topramezone. Mesotrione and tembotrione are examples of triketone $p$-hydroxyphenylpyruvate dioxygenase (HPPD) inhibiting herbicides, while topramezone belongs to the pyrazole subclass of HPPD-inhibiting herbicides.

research involving gene cloning, promoter analysis, and generation of transgenic plants overexpressing AtuGSTF2 is required to further support this hypothesis.

\section{Ongoing Research Investigating Unique Mechanisms Conferring Resistance to Topramezone and Carfentrazone- Ethyl in Amaranthus tuberculatus}

The MCR population also demonstrated resistance to topramezone (Hausman et al. 2011), another HPPD inhibitor having a distinct pyrazole structure (Ndikuryayo et al. 2017) compared with the triketone structures of mesotrione and tembotrione (Figure 13). Initial biochemical studies with excised leaves and whole plants indicated that an elevated rate of oxidative metabolism confers topramezone resistance in the MCR population relative to two HPPD-sensitive A. tuberculatus populations (Ma et al. 2018). However, the metabolic route for topramezone identified in MCR is different from the rapid initial $\mathrm{N}$-demethylation reaction that occurs in tolerant maize (Grossmann and Ehrhardt 2007). Recent research determined that two hydroxytopramezone metabolites are predominantly formed in MCR, which are only present in minor amounts in maize and HPPDsensitive A. tuberculatus (Lygin et al. 2018). Finally, MCR displayed foliar resistance to carfentrazone-ethyl but sensitivity to diphenylethers, a different class of PPO inhibitors compared with carfentrazone-ethyl (an aryl triazinone). Carfentrazone-ethyl resistance in the MCR population is not due to a glycine codon deletion or arginine substitution in the PPO2 enzyme; it is more likely conferred through an NTSR mechanism such as enhanced oxidative metabolism (unpublished data), although additional research is required to test this hypothesis.

\section{Conclusions}

Several weed populations around the world have evolved resistance to herbicides by metabolizing herbicide active ingredients to non-phytotoxic metabolites. Characterization of metabolic resistance mechanisms and underlying biochemical and molecular regulation is a difficult and arduous process. However, recent strides made through the use of contemporary approaches and procedures have made it possible to delineate roles of enzyme systems such as CYPs, GSTs, and GTs in metabolic and multiple resistance to herbicides in plants, including both crops and weeds, as outlined in this review. These biochemical and molecular mechanisms conferring resistance to multiple herbicides with different sites of action indicate weeds possess multiple genes encoding diverse metabolic enzymes, which ultimately result in complex, herbicide-dependent, cross- or multiple-resistance patterns. Cross- and multiple herbicide resistance could pose serious challenges for weed management in the future, especially if these resistance mechanisms do not confer a fitness cost to the plant in the absence of herbicide (Délye 2013; Yu and Powles 2014). Additionally, herbicide resistance due to rapid herbicide metabolism has the potential to confer resistance not only to existing commercial herbicides, but also to new or yet-to-bediscovered active ingredients ( $\mathrm{Yu}$ and Powles 2014). A better understanding of the biochemical, molecular, and genetic mechanisms conferring metabolic resistance to multiple herbicides provides insights into evolving weed populations in response to selection pressures and development of innovative and integrated resistant weed management strategies and demonstrates an urgent need for discovery of a new herbicide site of action (Duke 2012).

Author ORCIDs. (iD) Vijay Nandula, https://orcid.org/0000-0001-5618-7634.

Supplementary material. To view supplementary material for this article, please visit https://doi.org/10.1017/wsc.2018.88

Acknowledgments. VKN gratefully recognizes funding from the Weed Science Society of America toward organizing a symposium at the 2018 WSSA annual meeting in Arlington, VA. DER acknowledges expert technical assistance from Anatoli V. Lygin, Mayandi Sivaguru, and Yousoon Baek, University of Illinois-Urbana. RE acknowledges the joint support of the Biotechnology and Biological Sciences Research Council (grant BB/L001489/1) and Agriculture and Horticulture Development Board (RD-2012-3807). No conflicts of interest have been declared.

\section{References}

Ahrens WH (1990) Enhancement of soybean (Glycine max) injury and weed control by thifensulfuron insecticide mixtures. Weed Technol 4:524-528

Anonymous (2018) Command 3ME herbicide label. http://www.cdms.net/ ldat/ld324004.pdf. Accessed: May 11, 2018

Arntz MA, DeLucia EH, Jordan N (2000) From fluorescence to fitness: variation in photosynthetic rate affects fecundity and survivorship. Ecology 81:2567-2576

Baerg RJ, Barrett M, Polge ND (1996) Insecticide and insecticide metabolite interactions with cytochrome P450 mediated activities in maize. Pestic Biochem Physiol 55:10-20

Baerson SR, Sanchez-Moreiras A, Pedrol-Bonjoch N, Schulz M, Kagan IA, Agarwal AK, Reigosa MJ, Duke SO (2005) Detoxification and transcriptome response in Arabidopsis seedlings exposed to the allelochemical benzoxazolin-2(3H)-one. J Biol Chem 280:21867-21881

Bakkali Y, Ruiz-Santaella JP, Osuna MD, Wagner H, Fischer AJ, DePrado R (2007) Late watergrass (Echinochloa phyllopogon): mechanisms involved in the resistance to fenoxaprop-p-ethyl. J Agric Food Chem 55:4052-4058 
Barroso AAM, de S Costa MG, Neto NJ, dos Santos JI, Balbuena TS, Carbonari CA, Alves PLCA (2018) Protein identification before and after glyphosate exposure in Lolium multiflorum genotypes. Pest Manag Sci 74:1125-1133

Beaudegnies R, Edmunds AJF, Fraser TEM, Hall RG, Hawkes TR, Mitchell G, Schaetzer J, Wendeborn S, Wibley J (2009) Herbicidal 4-hydroxyphenylpyruvate dioxygenase inhibitors-a review of the triketone chemistry story from a Syngenta perspective. Bioorg Med Chem 17:4134-4152

Behringer C, Bartsch K, Schaller A (2011) Safeners recruit multiple signalling pathways for the orchestrated induction of the cellular xenobiotic detoxification machinery in Arabidopsis. Plant Cell Environ 34:1970-1985

Bernal J, Martin MT, Soto ME, Nozal MJ, Marotti I, Dinelli G, Bernal JL (2012) Development and application of a liquid chromatography-mass spectrometry method to evaluate the glyphosate and aminomethylphosphonic acid dissipation in maize plants after foliar treatment. J Agric Food Chem 60:4017-4025

Bjarnholt N, Neilson EHJ, Crocoll C, Jørgensen K, Motawia MS, Olsen CE, Dixon DP, Edwards R, Møller BL (2018) Glutathione transferases catalyze recycling of auto-toxic cyanogenic glucosides in sorghum. Plant J 94:1109-1125

Bohm GMB, Rombaldi CV, Genovese MI, Castilhos D, Alves BJR, Rumjanek NG (2014) Glyphosate effects on yield, nitrogen fixation, and seed quality in glyphosate-resistant soybean. Crop Sci 54:1737-1743

Bøhn T, Cuhra M, Traavik T, Sanden M, Fagan J, Primicerio R (2014) Compositional differences in soybeans on the market: glyphosate accumulates in Roundup Ready GM soybeans. Food Chem 153: 207-215

Boutsalis P, Gill GS, Preston C (2012) Incidence of herbicide resistance in rigid ryegrass (Lolium rigidum) across southeastern Australia. Weed Technol 26:391-398

Brazier-Hicks M, Knight KM, Sellars JD, Steel PG, Edwards R (2018) Testing a chemical series inspired by plant stress oxylipin signaling agents for herbicide safening activity. Pest Manag Sci 74:828-836

Broster JC, Pratley JE (2006) A decade of monitoring herbicide resistance in Lolium rigidum in Australia. Aust J Exp Agric 46:1151-1160

Brown HM (1990) Mode of action, crop selectivity, and soil relations of the sulfonylurea herbicides. Pest Manag Sci 29:263-281

Burnet MW, Loveys BR, Holtum JA, Powles S (1993) Increased detoxification is a mechanism of simazine resistance in Lolium rigidum. Pestic Biochem Physiol 46:207-218

Burns EE, Keith BK, Rafai MY, Bothner B, Dyer WE (2017) Proteomic and biochemical assays of glutathione-related proteins in susceptible and multiple herbicide resistant Avena fatua L. Pestic Biochem Physiol 140:69-78

Busi R, Gaines TA, Powles S (2017) Phorate can reverse P450 metabolismbased herbicide resistance in Lolium rigidum. Pest Manag Sci 73:410-417

Busi R, Gaines TA, Vila-Aiub MM, Powles SB (2014) Inheritance of evolved resistance to a novel herbicide (pyroxasulfone). Plant Sci 217:127-134

Busi R, Gaines TA, Walsh MJ, Powles SB (2012) Understanding the potential for resistance evolution to the new herbicide pyroxasulfone: field selection at high doses versus recurrent selection at low doses. Weed Res 52:489-499

Busi R, Neve P, Powles S (2013) Evolved polygenic herbicide resistance in Lolium rigidum by low-dose herbicide selection within standing genetic variation. Evol Appl 6:231-242

Busi R, Porri A, Gaines TA, Powles SB (2018) Pyroxasulfone resistance in Lolium rigidum is metabolism-based. Pestic Biochem Physiol 148:74-80

Busi R, Powles SB (2013) Cross-resistance to prosulfocarb and triallate in pyroxasulfone-resistant Lolium rigidum. Pest Manag Sci 69:1379-1384

Busi R, Powles SB (2016) Cross-resistance to prosulfocarb $+S$-metolachlor and pyroxasulfone selected by either herbicide in Lolium rigidum. Pest Manag Sci 72:1664-1672

Busk PK, Möller BL (2002). Dhurrin synthesis in sorghum is regulated at the transcriptional level and induced by nitrogen fertilization in older plants. Plant Physiol 129:1221-1231

Chample JR, Shaner D (1982) Enhanced phytotoxicity of bentazon with organophosphate and carbamate insecticides. Weed Sci 30:324-326

Chang JM, Knoz MJ, Aly EA, Sticker RE, Wilson KR, Krog NE, Dickinson PE (1987) 3-isoxazolidinones and related compounds. A new class of herbicides. Pages 10-23 in Baker DR, Fenyes JG, Moberg WK, Cross B, eds. Synthesis and Chemistry of Agrochemicals (ACS Symposium Series 355). Washington, DC: American Chemical Society
Christeller JT, Galis I (2014) $\alpha$-Linolenic acid concentration and not wounding per se is the key regulator of octadecanoid (oxylipin) pathway activity in rice (Oryza sativa L.) leaves. Plant Physiol Biochem 83:117-125

Christopher JT, Powles SB, Liljegren DR, Holtum JA (1991) Cross-resistance to herbicides in annual ryegrass (Lolium rigidum): II. chlorsulfuron resistance involves a wheat-like detoxification system. Plant Physiol 95:1036-1043

Christopher JT, Preston C, Powles SB (1994) Malathion antagonizes metabolism-based chlorsulfuron resistance in Lolium rigidum. Pestic Biochem Physiol 49:172-182

Clevenger KD, Bok JW, Ye R, Miley GP, Verdan MH, Velk T, Chen C, Yang K, Robey MT, Gao P, Lamprecht M, Thomas PM, Islam MN, Palmer JM, Wu CC, Keller NP, Kelleher NL (2017) A scalable platform to identify fungal secondary metabolites and their gene clusters. Nat Chem Biol 13:895-901

Conard S, Radosevich S (1979) Ecological fitness of Senecio vulgaris and Amaranthus retroflexus biotypes susceptible or resistant to atrazine. J Appl Ecol 16:171-177

Cook D, Rimando AM, Clemente TE, Schröder J, Dayan FE, Nanayakkara NPD, Pan Z, Noonan BP, Fishbein M, Abe I, Duke SOScott R., Baerson SR (2010) Alkylresorcinol synthases expressed in Sorghum bicolor root hairs play an essential role in the biosynthesis of the allelopathic benzoquinone sorgoleone. Plant Cell 22:867-887

Corrêa EL, Dayan FE, Owen DL, Rimando AM, Duke SO (2016) Glyphosateresistant and conventional canola (Brassica napus L.) responses to glyphosate and aminomethylphosponic acid (AMPA) treatment. J Agric Food Chem 64:3508-3513

Costea M, Weaver SE, Tardif FJ (2005) The biology of invasive alien plants in Canada. 3. Amaranthus tuberculatus (Moq.) Sauer var. rudis (Sauer) Costea \& Tardif. Can J Plant Sci 85:507-522

Cotterman J, Saari L (1992) Rapid metabolic inactivation is the basis for crossresistance to chlorsulfuron in diclofop-methyl-resistant rigid ryegrass (Lolium rigidum) biotype SR484. Pestic Biochem Physiol 43:182-192

Croteau R (1992) Clomazone does not inhibit the conversion of isopentyl pyrophosphate to geranyl, farnesyl, or geranyl geranyl pyrophosphate in vitro. Plant Physiol 98:1515-1517

Culpepper AS, York AC, Marth JL, Corbin FT (2001) Effect of insecticides on clomazone absorption, translocation, and metabolism in cotton. Weed Sci 49:613-616

Cummins I, Bryant DN, Edwards R (2009) Safener responsiveness and multiple herbicide resistance in the weed black-grass (Alopecurus myosuroides). Plant Biotechnol J 7:807-820

Cummins I, Cole DJ, Edwards R (1999) A role for glutathione transferases functioning as glutathione peroxidases in resistance to multiple herbicides in black-grass. Plant J 18:285-292

Cummins I, Dixon DP, Freitag-Pohl S, Skipsey M, Edwards R (2011) Multiple roles for plant glutathione transferases in xenobiotic detoxification. Drug Metab Rev 43:266-280

Cummins I, Wortley DJ, Sabbadin F, He Z, Coxon CR, Straker HE, Sellars JD, Knight K, Edwards L, Hughes D, Kaundun SS, Hutchings SJ, Steel PG, Edwards R (2013) Key role for a glutathione transferase in multipleherbicide resistance in grass weeds. Proc Natl Acad Sci USA 110: 5812-5817

Cuyamendous C, Leung KS, Durand T, Lee JC-Y, Oger C, Galano JM (2015) Synthesis and discovery of phytofurans: metabolites of $\alpha$-linolenic acid peroxidation. Chem Comm 51:15696-15699

Dailey F, Cronan J (1986) Acetohydroxy acid synthase I, a required enzyme for isoleucine and valine biosynthesis in Escherichia coli $\mathrm{K}-12$ during growth on acetate as the sole carbon source. J Bacteriol 165:453-460

Dancer JE, Hughes RG, Lindell SD (1997) Adenosine-5'-phosphate deaminase: a novel herbicide target. Plant Physiol 114:119-129

Dayan FE, Duke SO, Sauldubois A, Singh N, McCurdy CR, Cantrell CL (2007) $p$-Hydroxyphenylpyruvate dioxygenase is a herbicidal target site for $\beta$-triketones from Leptospermum scoparium. Phytochemistry 68: 2004-2014 
Dayan FE, Howell JL, Weidenhamer JD (2009) Dynamic root exudation of sorgoleone and its in planta mechanism of action. J Exp Bot 60:2107-2117

Dayan FE, Kuhajek JM, Canel C, Watson SB, Moraes RM (2003) Podophyllum peltatum possesses a $\beta$-glucosidase with high substrate specificity for the aryltetralin lignan podophyllotoxin. Biochim Biophys Acta 1646:157-163

Dayan FE, Rimando AM, Tellez MR, Scheffler BE, Roy T, Abbas HK, Duke SO (2002) Bioactivation of the fungal phytotoxin 2,5-anhydro-d-glucitol by glycolytic enzymes is an essential component of its mechanism of action. Z Naturforsch 57C:645-653

Debban CL, Okum S, Pieper KE, Wilson A, Baucom RS (2015) An examination of fitness costs of glyphosate resistance in the common morning glory, Ipomoea purpurea. Ecol Evol 5:5284-5294

de Carvalho LB, Alves PLCA, González-Torralva F, Cruz-Hipolito HE, Rojano-Delgado AM, De Prado R, Gil-Humanes J, Barro F, de Castro MDL (2012) Pool of resistance mechanisms to glyphosate in Digitaria insularis. J Agric Food Chem 60:615-622

Délye C (2013) Unravelling the genetic bases of non-target-site-based resistance (NTSR) to herbicides: a major challenge for weed science in the forthcoming decade. Pest Manag Sci 69:176-187

Délye C, Causse R, Gautier V, Poncet C, Michel S (2015) Using nextgeneration sequencing to detect mutations endowing resistance to pesticides: application to acetolactate-synthase (ALS) based resistance in barnyard-grass, a polyploid grass weed. Pest Manag Sci 71:675-685

DeRidder BP, Goldsbrough PB (2006) Organ-specific expression of glutathione $S$-transferases and the efficacy of herbicide safeners in Arabidopsis. Plant Physiol 140:167-175

Diehl KE, Stoller EW, Barrett M (1995) In vivo and in vitro inhibition of nicosulfuron metabolism by terbufos metabolites in maize Pestic Biochem Physiol 51:137-149

Dinelli G, Marotti I, Bonetti A, Catizone P, Urbano JM, Barnes J (2008) Physiological and molecular bases of glyphosate resistance in Conyza bonariensis biotypes from Spain. Weed Res 48:257-265

Dinelli G, Marotti I, Bonetti A, Minelli M, Catizone P, Barnes J (2006) Physiological and molecular insight on the mechanisms of resistance to glyphosate in Conyza canadensis (L.) Cronq. biotypes. Pestic Biochem Physiol 86:30-41

Dixon DP, Edwards R (2010) Glutathione transferases. Arabidopsis Book 8: e0131, 10.1199/tab.0131

Dixon DP, Hawkins T, Hussey PJ, Edwards R (2009) Enzyme activities and subcellular localization of members of the Arabidopsis glutathione transferase superfamily. J Exp Bot 60:1207-1218

Dueckershoff K, Mueller S, Mueller MJ, Reinders J (2008) Impact of cyclopentenone-oxylipins on the proteome of Arabidopsis thaliana. Biochim Biophys Acta 1784:1975-1985

Duhoux A, Carrère S, Duhoux A, Délye C (2017a) Transcriptional markers enable identification of rye-grass (Lolium sp.) plants with non-target-sitebased resistance to herbicides inhibiting acetolactate-synthase. Plant Sci 257:22-36

Duhoux A, Carrère S, Gouzy J, Bonin L, Délye C (2015) RNA-Seq analysis of rye-grass transcriptomic response to an herbicide inhibiting acetolactatesynthase identifies transcripts linked to non-target-site-based resistance. Plant Mol Biol 87:473-487

Duhoux A, Pernin F, Desserre D, Délye C (2017b) Herbicide safeners decrease sensitivity to herbicides inhibiting acetolactate-synthase and likely activate non-target-site-based resistance pathways in the major grass weed Lolium sp (rye-grass). Front Plant Sci 8:1310

Duke SO (1988) Glyphosate. Pages 1-70, in Kearney PC, Kaufman DD, eds. Herbicides-Chemistry, Degradation and Mode of Action. Volume 3. New York: Marcel Dekker

Duke SO (2011) Glyphosate degradation in glyphosate-resistant and -susceptible crops and weeds. J Agric Food Chem 59:5835-5841

Duke SO (2012) Why have no new herbicide modes of action appeared in recent years? Pest Manag Sci 68:505-512

Duke SO (2018) The history and current status of glyphosate. Pest Manag Sci 74:1027-1034

Duke SO, Dayan FE (2015) Discovery of new herbicide modes of action with natural phytotoxins. Pages 79-92 in Maienfisch P, Stevenson TM, eds. Discovery and Synthesis of Crop Protection Products (American Chemical
Society Symposium Series 1204). Washington, DC: American Chemical Society

Duke SO, Kenyon WH (1986) Effects of dimethazone (FMC 57020) on chloroplast development. II. Pigment synthesis and photosynthetic function in cowpea (Vigna unguiculate L.) primary leaves. Pestic Biochem Physiol 25:11-17

Duke SO, Rimando AM, Pace PF, Reddy KN, Smeda RJ (2003) Isoflavone, glyphosate, and aminomethylphosphonic acid levels in seed of glyphosatetreated, glyphosate-resistant soybean. J Agric Food Chem 51:340-344

Duke SO, Rimando AM, Reddy KN, Cizdziel JV, Bellaloui N, Shaw DR, Williams MM, Maul JE (2018) Lack of transgene and glyphosate effects on yield, and mineral and amino acid content of glyphosate-resistant soybean. Pest Manag Sci 74:1166-1173

Durand T, Bultel-Poncé V, Guy A, El Fangour S, Rossi JC, Galano JM (2011) Isoprostanes and phytoprostanes: bioactive lipids. Biochimie 93:52-60

El-Naggar SF, Creekmore RW, Schocken MJ, Rosen RT, Robinson RA (1992) Metabolism of clomazone herbicide in soybean. J Agric Food Chem 40:880-883

Evans AF, O'Brien SR, Ma R, Hager AG, Riggins CW, Lambert KN, Riechers DE (2017) Biochemical characterization of metabolism-based atrazine resistance in Amaranthus tuberculatus and identification of an expressed GST associated with resistance. Plant Biotechnol J 15:1238-1249

Feng PCC, Tran M, Chiu T, Sammons RD, Heck GR, CaJacob CA (2004) Investigations into glyphosate-resistant horseweed (Conyza canadensis): retention, uptake, translocation, and metabolism. Weed Sci 52:498-505

Ferguson GM, Hamill AS, Tardif FJ (2001) ALS inhibitor resistance in populations of Powell amaranth and redroot pigweed. Weed Sci 49:448-453

Ferhatoglu Y, Avdiushko S, Barrett M (2005) The basis for the safening of phorate insecticide phorate in cotton and inhibitors of cytochrome P450s Pestic Biochem Physiol 81:59-70

Ferhatoglu Y, Barrett M (2006) Studies of clomazone mode of action. Pestic Biochem Physiol 85:7-14

Figueiredo MR, Leibhart LJ, Reicher ZJ, Tranel PJ, Nissen SJ, Westra P, Bernards ML, Kruger GR, Gaines TA, Jugulam M (2018) Metabolism of 2,4-dichlorophenoxyacetic acid contributes to resistance in a common waterhemp (Amaranthus tuberculatus) population. Pest Manag Sci 74:2356-2362

Fischer AJ, Ateh CM, Bayer DE, Hill JE (2000a) Herbicide-resistant Echinochloa oryzoides and E. phyllopogon in California Oryza sativa fields. Weed Sci 48:225-230

Fischer AJ, Bayer DE, Carriere MD, Ateh CM, Yim K-O (2000b) Mechanisms of resistance to bispyribac-sodium in an Echinochloa phyllopogon accession. Pestic Biochem Physiol 68:156-165

Flagel LE, Wendel JF (2009) Gene duplication and evolutionary novelty in plants. New Phytol 183:557-564

Foes MJ, Liu L, Vigue G, Stoller EW, Wax LM, Tranel PJ (1999) A kochia (Kochia scoparia) biotype resistant to triazine and ALS-inhibiting herbicides. Weed Sci 47:20-27

Fonne-Pfister R, Chemla P, Ward E, Girardet M, Kreuz KE, Honzatko RB, Fromm HJ, Schar H-P, Grutter MG, Cowan-Jacob SW (1996) The mode of action and structure of a herbicide in complex with its target: Binding of activated hydantocidin to the feedback regulation site of adenylosuccinate synthetase. Proc Natl Acad Sci USA 93:9431-9436

Frear DS (1968) Microsomal $N$-demethylation, by a cotton leaf oxidase system, of 3-(4'-chlorophenyl)-1,1-dimethylurea (Monuron). Science 162:674-675

Frear DS, Swanson HR, Tanaka FS (1969) N-demethylation of substituted 3(phenyl)-1-methylureas: isolation and characterization of a microsomal mixed function oxidase from cotton. Phytochemistry 8:2157-2169

Gaines TA, Lorentz L, Figge A, Herrmann J, Maiwald F, Ott M-C, Han H, Busi R, Yu Q, Powles SB, Beffa R (2014) RNA-Seq transcriptome analysis to identify genes involved in metabolism-based diclofop resistance in Lolium rigidum. Plant J 78:865-876

Gao Q-M, Zhu S, Pradeep Kachroo P, Kachroo A (2015) Signal regulators of systemic acquired resistance. Front Plant Sci 6:228

Gardin JA, Gouzy J, Carrere S, Delye C (2015) ALOMYbase, a resource to investigate non-target-site-based resistance to herbicides inhibiting acetolactate-synthase (ALS) in the major grass weed Alopecurus myosuroides (black-grass). BMC Genomics 16:590 
Gonzalez VM, Kazimir J, Nimbal C, Weston LA, Cheniae GM (1997) Inhibition of a photosystem II electron transfer reaction by the natural product sorgoleone. J Agric Food Chem 45:1415-1421

Gonzalez-Torralva F, Gil-Humanes J, Barro F, Brants I, De Prado R (2012a) Target site mutation and reduced translocation are present in a glyphosateresistant Lolium multiflorum Lam. biotype from Spain. Plant Physiol Biochem 58:16-22

Gonzalez-Torralva F, Rojano-Delgado AM, de Castro MDL, Muellender N, De Prado R (2012b) Two non-target mechanisms are involved in glyphosateresistant horseweed (Conyza canadensis L. Cronq.) biotypes. J Plant Physiol 169:1673-1679

Goodrich LV, Butts-Wilmsmeyer CJ, Bollero GB, Riechers DE (2018) Sequential pyroxasulfone applications with fluxofenim reduce sorghum injury and increase weed control. Agron J 110:1915-1924

Govindarajan S, Mannervik B, Silverman JA, Wright K, Regitsky D, Hegazy U, Purcell TJ, Welch M, Minshull J, Gustafsson C (2015) Mapping of amino acid substitutions conferring herbicide resistance in wheat glutathione transferase. ACS Synth Biol 4:221-227

Gray JA, Balke NE, Stoltenberg DE (1996) Increased glutathione conjugation of atrazine confers resistance in a Wisconsin velvetleaf (Abutilon theophrasti) biotype. Pestic Biochem Physiol 55:157-171

Green JM (2009) Evolution of glyphosate-resistant crop technology. Weed Sci 57:108-117

Gronwald JW (1994) Resistance to photosystem II: inhibiting herbicides. Pages 27-60 in Powles SB, Holtum JAM, eds. Herbicide Resistance in Plants: Biology and Biochemistry. Boca Raton, FL: CRC Press

Grossmann K, Ehrhardt T (2007) On the mechanism of action and selectivity of the corn herbicide topramezone: a new inhibitor of 4hydroxyphenylpyruvate dioxygenase. Pest Manag Sci 63:429-39

Grossmann K, Kwiatkowski J (1993) Selective induction of ethylene and cyanide biosynthesis appears to be involved in the selectivity of the herbicide quinclorac between rice and barnyardgrass. J Plant Physiol 142:457-466

Guo J, Riggins CW, Hausman NE, Hager AG, Riechers DE, Davis AS, Tranel PJ (2015) Nontarget-site resistance to ALS inhibitors in waterhemp (Amaranthus tuberculatus). Weed Sci 63:399-407

Guo L, Qiu J, Ye C, Jin G, Mao L, Zhang H, Yang X, Peng Q, Wang Y, Jia L, Lin Z, Li G, Fu F, Liu C, Chen L, Shen E, Wang W, Chu Q, Wu D, Wu S, Xia C, Zhang Y, Zhou X, Wang L, Wu L, Song W, Wang Y, Shu Q, Aoki D, Yumoto E, Yokota T, Miyamoto K, Okada K, Kim D-S, Cai D, Zhang C, Lou Y, Qian Q, Yamaguchi H, Yamane H, Kong C-H, Timko MP, Bai L, Fan L (2017) Echinochloa crus-galli genome analysis provides insight into its adaptation and invasiveness as a weed. Nature communications 18:1031

Guttieri MJ, Eberlein CV, Thill DC (1995) Diverse mutations in the acetolactate synthase gene confer chlorsulfuron resistance in kochia (Kochia scoparia) biotypes. Weed Sci 43:175-178

Hager AG, Wax LM, Stoller EW, Bollero GA (2002) Common waterhemp (Amaranthus rudis) interference in soybean. Weed Sci 50:607-610

Halkier BA, Möller BL (1989) Biosynthesis of the cyanogenic glucoside dhurrin in seedlings of Sorghum bicolor (L.) Moench and partial purification of the enzyme system involved. Plant Physiol 90:1552-1559

Hammer PE, Hinson TK, Duck NB, Koziel (2007) May 10. Methods to confer herbicide resistance. US patent application 20070107078 A1, 1-53

Han H, Yu Q, Cawthray GR, Powles SB (2013) Enhanced herbicide metabolism induced by 2,4-D in herbicide susceptible Lolium rigidum provides protection against diclofop-methyl. Pest Manag Sci 69:996-1000

Han H, Yu Q, Owen MJ, Cawthray GR, Powles SB (2016) Widespread occurrence of both metabolic and target site herbicide resistance mechanisms in Lolium rigidum populations. Pest Manag Sci 72:255-263

Han H, Zhu B, Fu X, You S, Wang B, Li Z, Zhao W, Peng R, Yao Q (2015) Overexpression of d-amino acid oxidase from Bradyrhizobium japonicum, enhances resistance to glyphosate in Arabidopsis thaliana. Plant Cell Rep 34:2043-2051

Handayani VDS, Tanno Y, Yamashita M, Tobina H, Ichihara M, Ishida Y, Sawada H (2017) influence of weed management measures on glyphosate resistance and endophyte infection in naturalized Italian ryegrass (Lolium multiflorum). Weed Biol Manag 17:84-90
Hausman NE, Singh S, Tranel PJ, Riechers DE, Kaundun SS, Polge ND, Thomas DA, Hager AG (2011) Resistance to HPPD-inhibiting herbicides in a population of waterhemp (Amaranthus tuberculatus) from Illinois, United States. Pest Manag Sci 67:258-261

Heap I (2018) The International Survey of Herbicide Resistant Weeds. www. weedscience.org. Accessed: May 7, 2018

Hoagland RE (1980) Effects of glyphosate on metabolism of phenolic compounds. VI. Effects of glyphosine and glyphosate metabolites on phenlalanine ammonia-lyase activity, growth, and protein, chlorophyll, and anthocyanin levels in soybean (Glycine max) seedlings. Weed Sci 28:393-400

Horak MJ, Peterson DE (1995) Biotypes of Palmer amaranth (Amaranthus palmeri) and common waterhemp (Amaranthus rudis) are resistant to imazethapyr and thifensulfuron. Weed Technol 9:192-195

Hou Q, Ufer G, Bartels D (2016) Lipid signalling in plant responses to abiotic stress. Plant Cell Environ 39:1029-1048

Huffman J, Hausman NE, Hager AG, Riechers DE, Tranel PJ (2015) Genetics and inheritance of nontarget-site resistances to atrazine and mesotrione in a waterhemp (Amaranthus tuberculatus) population from Illinois. Weed Sci 63:799-809

Iwakami S, Endo M, Saika H, Okuno J, Nakamura N, Yokoyama M, Watanabe H, Toki S, Uchino A, Inamura T (2014a) Cytochrome P450 CYP81A12 and CYP81A21 are associated with resistance to two acetolactate synthase inhibitors in Echinochloa phyllopogon. Plant Physiol 165:618-629

Iwakami S, Uchino A, Kataoka Y, Shibaike H, Watanabe H, Inamura T (2014b) Cytochrome P450 genes induced by bispyribac-sodium treatment in a multiple-herbicide resistant biotype of Echinochloa phyllopogon. Pest Manag Sci 70:549-558

Iwakami S, Uchino A, Watanabe H, Yamasue Y, Inamura T (2012) Isolation and expression of genes for acetolactate synthase and acetyl-CoA carboxylase in Echinochloa phyllopogon, a polyploid weed species. Pest Manag Sci 68:1098-1106

Kaloumenos NS, Chatzilazaridou SL, Mylona PV, Polidoros AN, Eleftherohorinos IG (2012) Target-site mutation associated with cross-resistance to ALS-inhibiting herbicides in late watergrass (Echinochloa oryzicola Vasing). Pest Manag Sci 69:865-873

Kaundun SS, Hutchings S-J, Dale RP, Howell A, Morris JA, Kramer VC, Shivrain VK, Mcindoe E (2017) Mechanism of resistance to mesotrione in an Amaranthus tuberculatus population from Nebraska, USA. PloS One 12: e0180095, 10.1371/journal.pone.0180095

Keith BK, Burns EE, Bothner B, Carey CC, Mazurie AJ, Hilmer JK, Biyiklioglu S, Budak H, Dyer WE (2017) Intensive herbicide use has selected for constitutively elevated levels of stress-responsive mRNAs and proteins in multiple herbicide-resistant Avena fatua L. Pest Manag Sci 73:2267-2281

Kihara J, Bationo A, Waswa B, Kimetu J, Vanlauwe B, Okeyo J, Mukalama J, Martius C (2012) Effect of reduced tillage and mineral fertilizer application on maize and soybean productivity. Exp Agric 48:159-175

Komoßa D, Gennity I, Sandermann H (1992) Plant metabolism of herbicides with C-P bonds: glyphosate. Pestic Biochem Physiol 43:85-94

Koo AJ (2018) Metabolism of the plant hormone jasmonate: a sentinel for tissue damage and master regulator of stress response. Phytochem Rev 17:51-80

Koskinen WC, Marek LJ, Hall KE (2016) Analysis of glyphosate and aminomethylphosponic acid in water, plant materials and soil. Pest Manag Sci 72:423-432.

Kraehmer H, Laber B, Rosinger C, Schulz A (2014) Herbicides as weed control agents: state of the art. I. Weed control research and safener technology: the path to modern agriculture. Plant Physiol 166:1119-1131

Kreuz K, Fonne-Pfister R (1992) Herbicide-insecticide interaction in maize: malathion inhibits cytochrome P450-dependent primisulfuron metabolism. Pestic Biochem Physiol 43:232-240

Kryuchkova YV, Burygin GL, Gogoleva NE, Gogolev YV, Chernyshova MP, Makarov OE, Fedorov EE, Turkovskaya OV (2014) Isolation and characterization of a glyphosate-degrading rhizosphere strain, Enterobacter cloacae K7. Microbiol Res 169:99-105

Kuklinsky-Sobral J, Araújo W, Mendes R, Pizzirani-Kleiner A, Azevedo J (2005) Isolation and characterization of endophytic bacteria from soybean 
(Glycine max) grown in soil treated with glyphosate herbicide. Plant Soil 273:91-99

Labrou NE, Papageorgiou AC, Pavli O, Flemetakis E (2015) Plant GSTome: structure and functional role in xenome network and plant stress response. Curr Opin Biotechnol 32:186-194

Larrieu A, Vernoux T (2016) How does jasmonate signaling enable plants to adapt and survive? BMC Biol 14:79

Lehtovaara P (1978) Oxidation of glycine by Phaseolus leghaemoglobin with associated catabolic reactions at the haem. Biochem J 176:351-358

Lichtenthaler HK (1999) The 1-deoxy-d-xylulose-5-phosphate pathway of isoprenoid biosynthesis in plants. Ann Rev Plant Physiol 50:47-65

Lichtenthaler HK, Schwender J, Disch A, Rohmer M (1997) Biosynthesis of isoprenoids in higher plant chloroplasts proceeds via a mevalonate independent pathway. FEBS Lett 400:271-274

Loeffler C, Berger S, Guy A, Durand T, Bringmann G, Dreyer M, von Rad U, Durner J, Mueller MJ (2005) $B_{1}$-phytoprostanes trigger plant defense and detoxification responses. Plant Physiol 137:328-340

Lutzov M, Beyer P, Kleining H (1990) The herbicide Command does not inhibit prenyl diphosphate-forming enzymes in plastids. Z Naturforsch 45C:856-858

Lygin AV, Kaundun SS, Morris JA, McIndoe E, Hamilton AR, Riechers DE (2018) Metabolic pathway of topramezone in multiple-resistant waterhemp (Amaranthus tuberculatus) differs from naturally tolerant maize. Front Plant Sci, 10.3389/fpls.2018.01644

Ma R, Evans AF, O'Brien SR, Obenland O, Lygin AV, Kaundun SS, Riechers DE (2018) Biochemical and molecular mechanisms conferring metabolic resistance to multiple herbicides in Amaranthus tuberculatus. Abstr Weed Sci Soc Amer 58:247

Ma R, Evans AF, Riechers DE (2016) Differential responses to atrazine applied preemergence and postemergence in two populations of atrazine-resistant waterhemp (Amaranthus tuberculatus) from Illinois. Agron J 108:1196-1202

Ma R, Kaundun SS, Tranel PJ, Riggins CW, McGinness DL, Hager AG, Hawkes T, McIndoe E, Riechers DE (2013) Distinct detoxification mechanisms confer resistance to mesotrione and atrazine in a population of waterhemp. Plant Physiol 163:363-377

Ma R, Skelton JJ, Riechers DE (2015) Measuring rates of herbicide metabolism in dicot weeds with an excised leaf assay. J Visual Exp 103:e53236, $10.3791 / 53236$

Manalil S, Busi R, Renton M, Powles SB (2011) Rapid evolution of herbicide resistance by low herbicide dosages. Weed Sci 59:210-217

Manalil S, Busi R, Renton M, Powles SB (2012) An herbicide-susceptible rigid ryegrass (Lolium rigidum) population made even more susceptible. Weed Sci 60:101-105

Maor R, Shirasu K (2005) The arms race continues: battle strategies between plants and fungal pathogens. Curr Op Microbiol 8:399-404

Matsumoto H, Riechers DE, Lygin AV, Baluska F, Sivaguru M (2015) Aluminum signaling and potential links with safener-induced detoxification in plants. Pages 1-35 in Panda S, Baluška F, eds. Aluminum Stress Adaptation in Plants (Signaling and Communication in Plants 24). Cham, Switzerland: Springer International

Matzenbacher FO, Bortoly ED, Kalsing A, Merotto A (2014) Distribution and analysis of the mechanisms of resistance of barnyardgrass (Echinochloa crus-galli) to imidazolinone and quinclorac herbicides. J Agric Sci 153:1044-1058

Miller KD, Irzyk GP, Fuerst E, McFarland JE, Barringer M, Cruz S, Eberle WJ, Föry W (1996) Identification of metabolites of the herbicide safener benoxacor isolated from suspension-cultured Zea mays cells 3 and 24 hours after treatment. J Agric Food Chem 44:3335-3341

Mitchell G, Bartlett DW, Fraser TEM, Hawkes TR, Holt DC, Townson JK, Wichert RA (2001) Mesotrione: a new selective herbicide for use in maize. Pest Manag Sci 57:120-128

Moore RC, Purugganan MD (2005) The evolutionary dynamics of plant duplicate genes. Curr Opin Plant Biol 8:122-128

Mosblech A, Feussner I, Heilmann I (2009) Oxylipins: structurally diverse metabolites from fatty acid oxidation. Plant Physiol Biochem 47:511-517

Mougin C, Polge N, Scalla R, Cabanne F (1991) Interaction of various agrichemicals with cytochrome P450 dependent monooxygenases of wheat cells. Pestic Biochem Physiol 40:1-11
Mueller MJ (2004) Archetype signals in plants: the phytoprostanes. Curr Opin Plant Biol 7:441-448

Mueller MJ, Berger S (2009) Reactive electrophilic oxylipins: pattern recognition and signalling. Phytochemistry 70:1511-1521

Mueller S, Hilbert B, Dueckershoff K, Roitsch T, Krischke M, Mueller MJ, Berger S (2008) General detoxification and stress responses are mediated by oxidized lipids through TGA transcription factors in Arabidopsis. Plant Cell 20:768-785

Nakka S, Godar AS, Thompson CR, Peterson DE, Jugulam M (2017a) Rapid detoxification via glutathione $S$ transferase (GST)-conjugation confers high level of atrazine resistance in Palmer amaranth (Amaranthus palmeri). Pest Manag Sci 73:2236-2243

Nakka S, Godar AS, Wani PS, Thompson CR, Peterson DE, Roelofs J, Jugulam M (2017b) Physiological and molecular characterization of hydroxyphenylpyruvate dioxygenase (HPPD)-inhibitor resistance in Palmer amaranth (Amaranthus palmeri S. Wats.). Front Plant Sci 8:555

Nakka S, Thompson CR, Peterson DE, Jugulam M (2017c) Target site-based and non-target site based resistance to ALS inhibitors in Palmer amaranth (Amaranthus palmeri). Weed Sci 65:681-689

Nandula VK, Reddy KN, Koger CH, Poston DH, Rimando AM, Duke SO (2012) Multiple resistance to glyphosate and pyrithiobac in Palmer amaranth (Amaranthus palmeri) from Mississippi and response to flumiclorac. Weed Sci 60:179-188

Nandula VK, Reddy KN, Rimando AM, Duke SP, Poston DH (2007) Glyphosate-resistant and -susceptible soybean (Glycine max) and canola (Brassica napus) dose response and metabolism relationships with glyphosate. J Agric Food Chem 55:3540-3545

Ndikuryayo F, Moosavi B, Yang W-C, Yang G-F (2017) 4Hydroxyphenylpyruvate dioxygenase inhibitors: from chemical biology to agrochemicals. J Agric Food Chem 65:8523-8537

Nelson DR, Schuler MA, Paquette SM, Werck-Reichhart D, Bak S (2004) Comparative genomics of rice and Arabidopsis. Analysis of 727 cytochrome P450 genes and pseudogenes from a monocot and a dicot. Plant Physiol 135:756-772

Neve P, Powles S (2005) Recurrent selection with reduced herbicide rates results in the rapid evolution of herbicide resistance in Lolium rigidum. Theor Appl Genet 110:1154-1166

Nicolia A, Ferradini N, Molla G, Biagetti E, Pollegioni L, Veronesi F, Rosellini D (2014) Expression of an evolved engineered variant of a bacterial glycine oxidase leads to glyphosate resistance in alfalfa. J Biotechnol 184:201-208.

Ober D (2005) Seeing double: gene duplication and diversification in plant secondary metabolism. Trends Plant Sci 10:444-449

Oettmeier W (1999) Herbicide resistance and supersensitivity in photosystem II. Cell Mol Life Sci 55:1255-1277

Okazaki Y, Saito K (2014) Roles of lipids as signaling molecules and mitigators during stress response in plants. Plant J 79:584-596

Osuna MD, Vidotto F, Fischer AJ, Bayer DE, De Prado R, Ferrero A (2002) Cross-resistance to bispyribac-sodium and bensulfuron-methyl in Echinochloa phyllopogon and Cyperus difformis. Pestic Biochem Physiol 73:9-17

Owen M, Martinez N, Powles S (2014) Multiple herbicide-resistant Lolium rigidum (annual ryegrass) now dominates across the Western Australian grain belt. Weed Res 54:314-324

Pan G, Zhang X, Liu K, Zhang J, Wu X, Zhu J, Tu J (2006) Map-based cloning of a novel rice cytochrome P450 gene CYP81A6 that confers resistance to two different classes of herbicides. Plant Mol Biol 61:933-943

Pan L, Wang Z, Cai J, Gao H, Zhao H, Dong L (2016) High-throughput sequencing reveals differential regulation of miRNAs in fenoxaprop-P-ethyl resistant Beckmannia syzigachne. Sci Rep 6:28725

Patzoldt WL, Tranel PJ (2007) Multiple ALS mutations confer herbicide resistance in waterhemp (Amaranthus tuberculatus). Weed Sci 55:421-428

Pollegioni L, Schonbrunn E, Siehl D (2011) Molecular basis of glyphosate resistance-different approaches through protein engineering. FEBS Lett 278:2753-2766

Powles SB, Yu Q (2010) Evolution in action: plants resistant to herbicides. Annu Rev Plant Biol 61:317-347

Preston C (2004) Herbicide resistance in weeds endowed by enhanced detoxification: complications for management. Weed Sci 52:448-453 
Preston C, Powles SB (1998) Amitrole inhibits diclofop metabolism and synergises diclofop-methyl in a diclofop-methyl-resistant biotype of Lolium rigidum. Pestic Biochem Physiol 62:179-189

Reddy KN, Cizdziel JV, Williams MM, Maul JE, Rimando AM, Duke SO (2018) Glyphosate resistance technology has minimal effect on maize mineral nutrition and yield. J Agric Food Chem 66:10139-10146

Reddy KN, Duke SO, Rimando AM (2004) Aminomethylphosphonic acid, a metabolite of glyphosate, causes injury in glyphosate-treated, glyphosateresistant soybean. J Agric Food Chem 52:5139-5143

Reddy KN, Rimando AM, Duke SO, Nandula VK (2008) Aminomethylphosphonic acid accumulation in plant species treated with glyphosate. J Agric Food Chem 56:2125-2130

Riar DS, Norsworthy JK, Bond JA, Bararpour MT, Wilson MJ, Scott RC (2012) Resistance of barnyardgrass (Echinochloa crus-galli) populations to acetolactate synthase-inhibiting herbicides. Int J Agron, 10.1155/2012/893953

Riar DS, Norsworthy JK, Srivastava V, Nandula V, Bond JA, Scott RC (2013) Physiological and molecular basis of acetolactate synthase-inhibiting herbicide resistance in barnyardgrass (Echinochloa crus-galli). J Agric Food Chem 61:278-289

Ribeiro DN, Nandula VK, Dayan FE, Rimando AM, Duke SO, Reddy KN, Shaw DR (2015) Possible glyphosate resistance mechanisms in pitted morningglory (Ipomoea lacunosa). J Agric Food Chem 63:1689-1697

Riechers DE, Green JM (2017) Crop selectivity and herbicide safeners: historical perspectives and development, safener-regulated gene expression, signaling, and new research directions. Pages 123-143 in Jugulam M, ed. Biology, Physiology and Molecular Biology of Weeds. Boca Raton, FL: CRC Press

Riechers DE, Kreuz K, Zhang Q (2010) Detoxification without intoxication: herbicide safeners activate plant defense gene expression. Plant Physiol 153:3-13

Riechers DE, Ma R, Baek Y, Goodrich L, Lygin AV, Brown PJ (2018) Herbicide safener-regulated transcripts and metabolites reveal complex signaling, defense, and detoxification pathways in grain sorghum shoots. Abstr Weed Sci Soc Amer 58:238

Riechers DE, Zhang Q, Xu FX, Vaughn KC (2003) Tissue-specific expression and localization of safener-induced glutathione $S$-transferase proteins in Triticum tauschii. Planta 217:831-840

Rishi A, Muni S, Kapur V, Nelson ND, Goyal A (2004) Identification and analysis of safener-inducible expressed sequence tags in Populus using a cDNA microarray. Planta 220:296-306

Rojano-Delgado AM, Cruz-Hipolito H, de Prado R, de Castro MDL, Franco AR (2012) Limited uptake, translocation and enhanced metabolic degradation contribute to glyphosate tolerance in Mucuna pruriens var. utilis plants. Phytochemistry 73:34-41

Ruiz-Santaella JP, De Prado R, Wagner J, Fischer AJ, Gerhards R (2006) Resistance mechanisms to cyhalofop-butyl in a biotype of Echinochloa phyllopogon (Stapf) Koss. from California. J Plant Dis Protect 20:95-100

Ruiz-Santaella JP, Fisher AJ, De Prado R (2003) Alternative control of two biotypes of Echinochloa phyllopogon susceptible and resistant to fenoxaprop-ethyl. Commun Agric Appl Biol Sci 68:403-407

Saika H, Horita J, Taguchi-Shiobara F, Nonaka S, Nishizawa-Yokoi A, Iwakami S, Hori K, Matsumoto T, Tanaka T, Itoh T, Yano M, Kaku K, Shimizu T, Toki S (2014) A novel rice cytochrome P450 gene, CYP72A31, confers tolerance to acetolactate synthase-inhibiting herbicides in rice and Arabidopsis. Plant Physiol 166:1232-1240

Sammons RD, Gaines TA (2014) Glyphosate resistance: state of knowledge. Pest Manag Sci 70:1367-1377

Sandell L, Amit J, Kruger GR (2012) Evaluation of a putative HPPD-resistant Palmer amaranth (Amaranthus palmeri) population in Nebraska. Page 82 in Proceedings of the 67th Annual Meeting of the North Central Weed Science Society. St Louis, MO: North Central Weed Science Society

Scarabel L, Varotto S, Sattin M (2007) A European biotype of Amaranthus retroflexus cross-resistant to ALS inhibitors and response to alternative herbicides. Weed Res 47:527-533

Schueffler A, Anke T (2014) Fungal natural products in research and development. Nat Prod Rep 31:1425-1448
Shaner D (1991) Mechanisms of resistance to acetolactate synthase/ acetohydroxyacid synthase inhibitors. Pages 187-198 in Duke SO, ed. Herbicide Resistance in Weeds and Crops. New York: Lewis

Sibony M, Michel A, Haas H, Rubin B, Hurle K (2001) Sulfometuron-resistant Amaranthus retroflexus: cross-resistance and molecular basis for resistance to acetolactate synthase-inhibiting herbicides. Weed Res 41:509-522

Sibony M, Rubin B (2003) Molecular basis for multiple resistance to acetolactate synthase-inhibiting herbicides and atrazine in Amaranthus blitoides (prostrate pigweed). Planta 216:1022-1027

Siehl DL, Castle LA, Gorton R, Keenan RJ (2007) The molecular basis of glyphosate resistance by an optimized microbial acetyltransferase. J Biol Chem 15:11446-11455

Skipsey M, Knight KM, Brazier-Hicks M, Dixon DP, Steel PG, Edwards R (2011) Xenobiotic responsiveness of Arabidopsis thaliana to a chemical series derived from a herbicide safener. J Biol Chem 286:32268-32276

Song J-S, Lim S-H, Yook M-J, Kim J-W, Kim D-S (2017) Cross-resistance of Echinochloa species to acetolactate synthase inhibitor herbicides. Weed Biol Manag 17:91-102

Steckel LE (2007) The dioecious Amaranthus spp.: here to stay. Weed Technol 21:567-570

Steckel LE, Sprague CL (2004) Common waterhemp interference in corn. Weed Sci 52:359-364

Takeda S, Erbes DL, Sweetser PB, Hay JV, Yuyama T (1986) Mode of herbicidal and selective action of DPX-F5384 between rice and weeds. J Weed Sci Tech 31:157-163

Taki N, Sasaki-Sekimoto Y, Obayashi T, Kikuta A, Kobayashi K, Ainai T, Yagi K, Sakurai N, Suzuki H, Masuda T, Takamiya K-I, Shibata D, Kobayashi Y, Ohta H (2005) 12-Oxophytodienoic acid triggers expression of a distinct set of genes and plays a role in wound-induced gene expression in Arabidopsis. Plant Physiol 139:1268-1283

Tétard-Jones C, Edwards R (2016) Potential roles for microbial endophytes in herbicide tolerance in plants. Pest Manag Sci 72:203-209

Tétard-Jones C, Sabbadin F, Moss S, Hull R, Neve P, Edwards R (2018) Unique changes in protein expression in black-grass associated with multiple routes to non-target site resistance towards herbicides. Plant J, $10.1111 /$ tpj. 13892

Theodoulou FL, Clark IM, He X-L, Pallett KE, Cole DJ, Hallahan DL (2003) Co-induction of glutathione $S$-transferases and multidrug resistance associated protein by xenobiotics in wheat. Pest Manag Sci 59:202-214

Thom R, Cummins I, Dixon DP, Edwards R, Cole DJ, Lapthorn AJ (2002) Structure of a tau class glutathione $S$-transferase from wheat active in herbicide detoxification. Biochemistry 41:7008-7020

Thompson C, Peterson D, Lally N (2012) Characterization of HPPD resistant Palmer amaranth. Proceedings of the 52nd Annual Conference of the Weed Science Society of America. Waikoloa, HI: Weed Science Society of America

Tranel PJ, Wright TR, Heap IM (2016) Mutations in herbicide-resistant weeds to ALS inhibitors. http://www.weedscience.org/Mutations/MutationDisplayAll.aspx. Accessed March 23, 2018

Varanasi VK, Godar AS, Currie RS, Dille AJ, Thompson CR, Stahlman PW, Jugulam M (2015) Field-evolved resistance to four modes of action of herbicides in a single kochia (Kochia scoparia L. Schrad.) population. Pest Manag Sci 71:1207-1212

Veldhuis LJ, Hall LM, O’Donovan JT, Dyer W, Hall JC (2000) Metabolismbased resistance of a wild mustard (Sinapis arvensis L.) biotype to ethametsulfuron-methyl. J Agric Food Chem 48:2986-2990

Verhoeven KJF, Biere A, Harvey JA, van der Putten WH (2009) Plant invaders and their novel natural enemies: who is naïve? Ecology Lett 12:107-117

Weimer MR, Balke NE, Buhler DD (1992) Herbicide clomazone does not inhibit in-vitro geranylgeranyl synthesis to mevanolate. Plant Physiol 98:427-432

Whaley CM, Wilson HP, Westwood JH (2006) ALS resistance in several smooth pigweed (Amaranthus hybridus) biotypes. Weed Sci 54:828-832

Whaley CM, Wilson HP, Westwood JH (2007) A new mutation in plant ALS confers resistance to five classes of ALS-inhibiting herbicides. Weed Sci 55:83-90 
Wild A, Ziegler C (1989) The effect of bialaphos on ammonium-assimilation and photosynthesis. I. Effect on the enzymes of ammonium-assimilation. Z Naturforsch 44C:97-102

Williams J (2000) Current and future grass herbicides in rice. Pages 123-128 in Proceedings of the California Weed Science Society

Wright AA, Nandula VK, Grier L, Showmaker KC, Bond JA, Peterson DG, Ray JD, Shaw DR (2016) Characterization of fenoxaprop-P-ethyl-resistant junglerice (Echinochloa colona) from Mississippi. Weed Sci 64:588-595

Wright AA, Rodriguez-Carres M, Sasidharan R, Koski L, Peterson DG, Nandula VK, Ray JD, Bond JA, Shaw DR (2018) Multiple herbicide resistant junglerice (Echinochloa colona): identification of genes potentially involved in resistance through differential gene expression analysis. Weed Sci 66:347-354

Wright AA, Sasidharan R, Koski L, Rodriguez-Carres M, Peterson DG, Nandula VK, Ray JD, Bond JA, Shaw DR (2017) Transcriptomic changes in Echinochloa colona in response to treatment with the herbicide imazamox. Planta 247:369-379

Yan Y, Christensen S, Isakeit T, Engelberth J, Meeley R, Hayward A, Emery RJN, Kolomiets MV (2012) Disruption of OPR7 and OPR8 reveals the versatile functions of jasmonic acid in maize development and defense. Plant Cell 24:1420-1436

Yasuor H, Milan M, Eckert JW, Fischer AJ (2012) Quinclorac resistance: a concerted hormonal and enzymatic effort in Echinochloa phyllopogon. Pest Manag Sci 68:108-115
Yasuor H, Osuna MD, Ortiz A, Saldain NE, Eckert JW, Fischer AJ (2009) Mechanism of resistance to penoxsulam in late watergrass [Echinochloa phyllopogon (Stapf) Koss.]. J Agric Food Chem 57:3653-3660

Yasuor H, Tenbrook PL, Tjeerdema RS, Fischer AJ (2008) Responses to clomazone and 5-ketoclomazone by Echinochloa phyllopogon resistant to multiple herbicides in Californian rice fields. Pest Manag Sci 64:1031-1039

Yasuor H, Zou W, Tolstikov VV, Tjeerdema RS, Fischer AJ (2010) Differential oxidative metabolism and 5-ketoclomazone accumulation are involved in Echinochloa phyllopogon resistance to clomazone. Plant Physiol 153:319-326

Yu Q, Han H, Cawthray GR, Wang SF, Powles SB (2013) Enhanced rates of herbicide metabolism in low herbicide-dose selected resistant Lolium rigidum. Plant Cell Environ 36:818-827

Yu Q, Powles S (2014) Metabolism-based herbicide resistance and crossresistance in crop weeds: a threat to herbicide sustainability and global crop production. Plant Physiol 166:1106-1118

Zhang Q, Xu FX, Lambert KN, Riechers DE (2007) Safeners coordinately induce the expression of multiple proteins and MRP transcripts involved in herbicide metabolism and detoxification in Triticum tauschii seedling tissues. Proteomics 7:1261-1278

Zhao N, Li W, Bai S, Guo WL, Yuan GH, Wang F, Liu WT, Wang JX (2017) Transcriptome profiling to identify genes involved in mesosulfuron-methyl resistance in Alopecurus aequalis. Front Plant Sci 8:1391 